\title{
Trade in Carbon and Carbon Tariffs
}

\section{Christoph Böhringer $^{1} \cdot$ Jan Schneider ${ }^{1}$ Emmanuel Asane-Otoo ${ }^{1}$}

Accepted: 23 February 2021 / Published online: 15 March 2021

(c) The Author(s) 2021

\begin{abstract}
Carbon-based import tariffs are proposed as a policy measure to reduce carbon leakage and increase the global cost-effectiveness of unilateral $\mathrm{CO}_{2}$ emission pricing. We investigate the case for carbon tariffs. For our assessment, we combine multi-region input-output and computable general equilibrium analyses based on data from the World Input-Output Database for the period 2000-2014. The multi-region input-output analysis confirms that carbon embodied in trade has increased during this period, but trade flows from Non-OECD to OECD countries became less important in relative terms since the 2007-2008 financial crisis. The computable general equilibrium analysis suggests that carbon tariffs' efficacy in combating leakage increases in periods when trade in carbon increases. However, its potential to improve the global-cost effectiveness of unilateral emission pricing remains modest. On the other hand, we find that the potential of carbon tariffs to shift the economic burden of $\mathrm{CO}_{2}$ emission reduction from abating developed regions to non-abating developing regions increases sharply between 2000 and 2007, but declines after the financial crisis.
\end{abstract}

Keywords Embodied carbon · Carbon tariffs · Unilateral climate policy · Computable general equilibrium

JEL Classification D57 · D58 · Q58

\section{Introduction}

Our interest in the analysis of carbon tariffs emerges from two major developments over the last two decades. First, despite the Paris Agreement in December 2015 to limit global warming to less than $2{ }^{\circ} \mathrm{C}$ above pre-industrial levels, there is still no global climate treaty which prescribes legally binding emission caps for individual countries. Many countries

Emmanuel Asane-Otoo

asane.otoo@uol.de

Christoph Böhringer

boehringer@uol.de

Jan Schneider

jan.schneider@uol.de

1 Department of Economics, University of Oldenburg, Ammerländer Heerstrasse 114-118, 26129 Oldenburg, Germany 
communicated their nationally determined contributions (NDCs) to reduce greenhouse gas (GHG) emissions. ${ }^{1}$ However-as opposed to the previous Kyoto Protocol-there is no legal enforcement mechanism if a set target is not achieved, and it remains to be seen how the NDCs will eventually lead to global emission pricing at stringent levels. Given the bleak prospects for globally coordinated stringent emission pricing, tariffs on the embodied carbon of goods imported from regions with lax or no emission regulations are considered as an important policy measure to foster the efficacy of unilateral emission pricing. ${ }^{2}$

Second, the global economy has undergone a substantial structural change regarding patterns of production, consumption, and trade. In particular, trade in carbon embodied in goods increased markedly until the 2007-2008 financial crisis due to the increased offshoring of emission-intensive production from developed countries to developing countries and has plateaued afterward. The $\mathrm{CO}_{2}$ intensity of traded goods, on the other hand, has decreased substantially. At the same time, (emission-intensive) electricity as a major input in production has gained importance, especially in developing regions. Against these developments, we evaluate the performance of embodied carbon tariffs as a complementary instrument to unilateral carbon pricing.

To date, the most comprehensive approach for transnational emission pricing is the European Union Emissions Trading Scheme (EU ETS), which entered into force in 2005, setting a cap on carbon emissions from energy-intensive sectors within the EU. In parallel, the number of jurisdictions-national and sub-national-where emission pricing instruments have been implemented has markedly increased over the past decade but still covers only 20-25\% of global GHG emissions (Métivier et al. 2018; World Bank 2018). ${ }^{3}$ The world community is thus still far off from comprehensive and harmonized GHG emission pricing. It is rather likely that a situation with stringent emission regulation in industrialized countries and no or weaker emission regulation in the developing world will prevail for quite some time.

However, a critical drawback of such disparate emission regulation is carbon leakage, i.e., the relocation of emissions from regulating countries to parts of the world economy subject to no or weaker regulation (Hoel 1991; Felder and Rutherford 1993). Leakage can occur through two main interrelated channels: the competitiveness channel and the fossilfuel price channel. ${ }^{4}$ As to the competitiveness channel, carbon pricing increases the production cost of emission-intensive and trade-exposed (EITE) sectors that lose in competitiveness against foreign un- or less regulated industries both on the domestic market as well as on foreign markets. This leads to production shifts in EITE sectors from regulated to unregulated regions, i.e., (positive) carbon leakage. The fossil-fuel price channel occurs

\footnotetext{
${ }^{1}$ For country-level NDCs, see https://www4.unfccc.int/sites/NDCStaging/Pages/All.aspx.

${ }^{2}$ Embodied carbon refers to the entire $\mathrm{CO}_{2}$ emitted to produce and supply a certain good to the destination market, i.e., direct $\mathrm{CO}_{2}$ emissions from fossil fuel combustion in the production process as well as indirect $\mathrm{CO}_{2}$ emissions to produce intermediate inputs such as electricity or international transportation services.

3 See Haites (2018) for a review of the performance of carbon pricing schemes across different jurisdictions.

${ }^{4}$ Some authors additionally identify a so-called investment channel, i.e., unilateral carbon pricing leads to differences in the return on capital and thus provides incentives for firms to direct investment towards countries or sectors with less stringent climate policies (Reinaud 2008; Dröge 2009; Vivid Economics and Ecofys 2014). Our static modeling framework is designed for a medium-term policy assessment that focuses on the allocative efficiency of the economies given fixed endowments with primary factors. While capital is mobile across sectors, we do not consider endogenous capital investment and depreciation. Thus, the focus in our analysis lies on the competitiveness channel and the fossil-fuel channel.
} 
when unilateral carbon pricing and reduced fossil fuel demand in emission-abating countries depress international fossil fuel prices, thereby incentivizing consumption in unregulated regions.

Given the global nature of the GHG emission externality, there are two major concerns associated with carbon leakage. First, leakage reduces the global cost-effectiveness of unilateral policies. Second, leakage could be a manifestation of undue excessive competitiveness losses for EITE industries in countries with stringent emission regulation. These concerns have fostered carbon tariffs' policy appeal in industrialized countries that pursue stringent domestic carbon pricing in the battle against climate change. ${ }^{5}$ As a prominent example, the then-candidate for President of the European Commission Ursula von der Leyen stated in the plenary of the European Parliament: ${ }^{6}$

Emissions must have a price that changes our behavior. To complement this work and to ensure our companies can compete on a level-playing field, I will introduce a Carbon Border Tax to avoid carbon leakage.

In order to extend the reach of domestic carbon regulation, carbon tariffs apply the domestic $\mathrm{CO}_{2}$ price as a tax on emissions embodied in imports from countries without (or with very lenient) emission regulation. In theory, supplemental carbon tariffs bear the potential to increase global cost-effectiveness compared to domestic emission pricing only and to level the playing field on markets for EITE goods. The policy appeal of carbon tariffs in terms of its impact on leakage, global cost-effectiveness, and competitiveness effects for EITE industries has been examined in a number of empirical studies. Fischer and Fox (2012), for example, investigate anti-leakage measures that could complement unilateral emission pricing and conclude that full border carbon adjustment is likely the most effective anti-leakage policy. ${ }^{7}$ Peterson and Schleich (2007) evaluate embodied carbon tariff options for the sectors covered by the EU ETS and find only marginal overall effects in terms of their capability to reduce carbon leakage.

Monjon and Quirion (2011) compare the effectiveness of various designs for border carbon adjustment and output-based allocation in reducing carbon leakage from EU ETS sectors. They conclude that border carbon adjustment is the most effective anti-leakage policy. Böhringer et al. (2014) investigate anti-leakage measures as a function of abatement coalition size and identify full border carbon adjustment as the superior measure to improve the global cost-effectiveness of unilateral emission pricing. They furthermore show that border carbon adjustments can moderate output declines for EITE industries.

A large number of empirical studies also emphasize the potential of carbon tariffs to shift the burden of unilateral climate policy from abating to non-abating regions through policy-induced changes in terms of trade (see e.g. Böhringer et al. 2018, 2012; Ghosh et al. 2012; Weitzel et al. 2012). Carbon tariffs can be used by industrialized abating countriesthat are net importers of embodied emissions from developing countries - to exert market

\footnotetext{
5 Besides the prospects of reducing carbon leakage and hence ameliorating anxieties regarding the loss of competitiveness in domestic industries, advocates of carbon tariffs also point out that unilateral policies geared towards emission abatement solely in domestic production sectors ignore the carbon footprint of imported goods and therefore amount to the shirking of polluter-pays responsibilities.

6 Opening Statement in the European Parliament Plenary Session by Ursula von der Leyen, Candidate for President of the European Commission. 16 July 2019. See https://ec.europa.eu/commission/presscorner/ detail/en/speech_19_4230.

7 Full border carbon adjustment consists of carbon tariffs on the import side and carbon-related rebates to exports.
} 
power and change the terms of trade in their favor. As a prime example, countries that are net exporters of fossil fuels are negatively affected since carbon tariffs depress international fuel prices by reducing global fossil fuel consumption.

To summarize: The bulk of empirical analysis on the implications of carbon tariffs comes up with two central findings (for summaries see e.g. Böhringer et al. 2012; Branger and Quirion 2014; Carbone and Rivers 2017). First, carbon tariffs are potent in reducing emission leakage and attenuating output losses for EITE industries. However, gains in global cost-effectiveness remain relatively modest. Second, carbon tariffs shift the economic burden of emission reductions from regulating developed regions to unregulated developing regions.

Empirical analyses so far have been based on pointwise assessments for specific baseyears without accounting for the fact that trade in embodied carbon has changed significantly over time. Primarily, in the period before the 2007-2008 financial crisis, industrialized OECD countries were large net importers, while developing Non-OECD countries were mostly large net exporters of embodied carbon (Wood et al. 2019; Peters and Hertwich 2008; Caldeira and Davis 2011; Peters et al. 2011). This raises the policy-relevant question how changing trade patterns in embodied carbon affects the case for (or against) carbon tariffs regarding (1) their potential to reduce carbon leakage, (2) their effect on the global cost-effectiveness of climate policy, and (3) the burden they impose on countries which face carbon tariffs.

Clearly, if there is no carbon embodied in trade at all, the implementation of carbon tariffs would have no effect. Thus, it seems plausible, on the one hand, that the potential of carbon tariffs to reduce leakage and increase the global cost-effectiveness of unilateral emission pricing augments in periods when trade in carbon increases. On the other hand, the burden-shifting effect might be at odds with industrialized countries' commitment to avoiding adverse economic spillover effects of their emission regulation to the developing world. ${ }^{8}$

We evaluate the performance of carbon tariffs along these lines by combining multiregion input-output (MRIO) and computable general equilibrium (CGE) analyses based on annual data from 2000 to 2014, provided by the World Input-Output Database (WIOD). Our empirical investigation shows that it is insufficient to only consider the growing amount of emissions embodied in trade, but that a more differentiated review of underlying drivers is required to explain the performance of carbon tariffs. The results from our MRIO analysis confirm that imports of embodied emissions in developed countries from developing countries have sharply increased between 2000 and 2007-2008 (the financial crisis) and have plateaued after 2010. A decomposition of $\mathrm{CO}_{2}$ intensity of OECD EITE goods production shows that the share of emissions stemming from imported (non-OECD) intermediate inputs almost doubled from about 11 in 2000 to $19 \%$ in 2014.

At first glance, this development contributes to the appeal of carbon tariffs, as more emissions can be taxed at the border. However, we add two important observations that refine the picture and reduce the efficacy of carbon tariffs regarding leakage reduction and global cost-effectiveness improvement. First, we find that the $\mathrm{CO}_{2}$ intensity of EITE production has declined. Notably, the $\mathrm{CO}_{2}$ intensity of EITE imports from Non-OECD to

\footnotetext{
${ }^{8}$ As a prominent example, the Kyoto Protocol explicitly reflected concerns on adverse terms-of-trade effects by postulating that developed countries '...shall strive to implement policies and measures ...in such a way as to minimize adverse ...economic impacts on other Parties, especially developing country Parties ...' (UNFCCC 1998, Article 2, paragraph 3).
} 
OECD has decreased from $2.75 \mathrm{~kg} / \mathrm{US} \$$ in 2000 to $1.33 \mathrm{~kg} / \mathrm{US} \$$ in 2014 . At the same time, emissions embodied in Non-OECD exports to OECD-as a share of production-based emissions in Non-OECD—have decreased from 51 in 2000 to $36 \%$ in 2014. That is, the relative importance of emission trade from Non-OECD to OECD has declined, in particular, compared to trade within Non-OECD. Second, we observe that a growing share of Non-OECD emissions stems from electricity production. Electricity is (almost) not traded internationally and can not be targeted directly by carbon tariffs. As a further refinement, it is useful to distinguish the emission-related observations based on our MRIO analysis in three different phases-pre-crisis (2000-2007), crisis (2008-2009), and post-crisis (2010-2014). ${ }^{9}$

Our CGE results covering the global economy for different observation years between 2000 and 2014 show a 64-80\% leakage reduction due to carbon tariffs. The impacts of carbon tariffs simulated in the CGE analysis can be traced back to different opposing developments in the underlying economic structure observed in the MRIO analysis. The increasing share of intra-Non-OECD trade allows Non-OECD countries to redirect trade flows more easily when targeted with carbon tariffs. Also, while carbon tariffs can narrow or even shut down the competitiveness channel for leakage, the expansion of the electricity sector increases the relative importance of the fossil-fuel price channel and therefore hampers the overall effectiveness of carbon tariffs against leakage. ${ }^{10}$ Our analysis of the efficacy of carbon tariffs provides policy-relevant insights. In particular, we caution against the simplistic proposition that an overall increase in global trade necessarily strengthens the case for carbon tariffs. The pattern of trade and structural changes in the economies over time drive the impacts of carbon tariffs. ${ }^{11}$

The remainder of this paper is organized as follows. In Sect. 2 we describe the data and the numerical models (MRIO and CGE) underlying our empirical analysis on the implications of carbon tariffs; we also present here the results of the MRIO analysis. In Sect. 3 we specify our counterfactual policy scenarios and interpret the CGE results. In Sect. 4 we conclude.

\section{Data and Numerical Models}

\subsection{Data}

Our analysis is based on the 2016 release of the World Input-Output Database (WIOD) see Timmer et al. $(2015,2016)$. WIOD provides time series of detailed input-output tables, trade flows, socio-economic, and $\mathrm{CO}_{2}$ emission data from 2000 to 2014. The period under consideration encompasses the years 2008-2009, where we observe the impact of the

\footnotetext{
9 While the international financial crisis was in 2007-2008, the impact on economic and emissions data is most pronounced for the years 2008-2009, which is why we refer to this period as the crisis in the context of the data.

${ }^{10}$ Effectiveness of carbon tariffs in this paper refers to the reduction of the reference case leakage rate through the application of border tariffs.

11 Note that our analysis does not take into account the strategic power of carbon tariffs (see for e.g. Böhringer et al. 2016). That is, the use of tariffs as a credible and effective threat to coerce unregulated regions to adopt emission reduction policies. Böhringer and Rutherford (2017) have, however, shown that improvement in the global cost-effectiveness of using carbon tariffs as a sanctioning instrument crucially hinges on the scope of retaliatory tariffs adopted by the unregulated region.
} 
global economic slowdown triggered by the international financial crisis in 2007-2008. WIOD features data for 56 sectors and 43 world regions. We aggregate the data to 5 sectors and 7 geopolitical regions, reflecting our primary interest in carbon trade between (industrialized) OECD regions and (developing) non-OECD regions. The sectors and regions incorporated in our model-based analysis are listed in Table 1.

To capture $\mathrm{CO}_{2}$ emission flows in the economy, we explicitly represent primary and secondary energy carriers: fossil fuels (included in the WIOD sector "mining and quarrying"), refined oil products, and electricity. Furthermore, we explicitly incorporate a composite sector of emission-intensive and trade-exposed (EITE) industries (rubber and plastics; basic metals and fabricated metals; chemical products; non-metallic minerals; and paper, pulp, and print) which are subject to carbon tariffs in most policy proposals for border carbon adjustments. As to regions, we include industrialized OECD economies that have undertaken or are contemplating unilateral emission pricing and the major developing Non-OECD economies that still refrain from stringent emission regulation.

\subsection{Multi-region Input-Output (MRIO) Analysis}

To develop an understanding of the changing patterns in embodied emission trade, we apply a multi-region input-output (MRIO) framework to annual historical data from 2000 to 2014. To calculate the region- and sector-specific $\mathrm{CO}_{2}$ intensity of goods, ${ }^{12}$ we use fundamental input-output accounting identities-see Appendix 3 for a detailed description of the MRIO model (see also Böhringer et al. 2018). After solving the associated system of linear equations, we can decompose the embodied emissions in goods according to their origin, i.e., whether they stem from the production process (through fossil fuel inputs) or are embodied in domestic or imported intermediate inputs. Our main insights from the MRIO are presented below.

\subsubsection{Trade in Emissions}

Figure 1 depicts the evolution of total and net imports of embodied $\mathrm{CO}_{2}$ emissions in OECD from Non-OECD countries, as well as total trade in embodied emissions among Non-OECD countries. The MRIO results indicate significant increases in both total imports and net imports of embodied emissions for the OECD. Total imports of embodied emissions in OECD countries - that could potentially be covered by carbon tariffsincreased by $50 \%$ from an initial level of $1866 \mathrm{Mt}$ of $\mathrm{CO}_{2}$ in 2000 to $2784 \mathrm{Mt}$ in 2014, while net imports increased by $30 \%$ from 1231 to over $1587 \mathrm{Mt}^{13}$ Figure 1 also reveals that these developments are not monotonic and are impacted by the financial crisis of 2007-2008. We observe a sharply increasing trend of OECD's net and total imports peaking in 2006 and 2007, respectively. Net and total OECD imports of embodied emissions decelerated significantly in 2009 and have since plateaued following a rebound between 2010 and 2011. Note that OECD import and net import levels post-2008 are relatively low compared to the peak levels in 2006-2007. Wood et al. (2019) attribute

\footnotetext{
$12 \mathrm{CO}_{2}$ intensity is defined as embodied $\mathrm{CO}_{2}$ emissions per USD of output.

13 The increase in net imports of embodied emissions in OECD is consequently mirrored by a declining OECD-share of global production-based ("direct") $\mathrm{CO}_{2}$ emissions: In 2000, global $\mathrm{CO}_{2}$ emissions from fossil fuel use amounted to $12642 \mathrm{Mt}$, of which $57 \%$ stemmed from OECD countries. In 2014, only $37 \%$ of the globally emitted $\mathrm{CO}_{2}(32198 \mathrm{Mt})$ is attributed to OECD countries.
} 
this finding to the reduction in the emissions intensity of traded goods, rather than the volume of trade.

Overall, three distinct phases of the evolution of OECD imports in embodied emissions can be observed. In the first phase-the pre-crisis from 2000 to 2007 -we observe an increasing trend that peaks in 2007, followed by the period 2008-2009, where we observe the full impact of the crisis. OECD imports and net imports of embodied emissions increase again and reach post-crisis highest levels-though below the peak pre-financial crisis level-in 2011 and have stabilized thereafter. Over time, trade in embodied emissions becomes more relevant for trade flows from Non-OECD to OECD countries and within Non-OECD. The intra Non-OECD trade of embodied emissions increased by a factor of 2.8 from 958 Mt to 2623 Mt between 2000 and 2014. This indicates a marked increase in emissions trade among developing Non-OECD countries. Most strikingly, unlike OECD imports, Non-OECD trade in embodied emissions continue to increase after the financial crisis.

The picture becomes more comprehensive if we consider relative changes over the period. Figure 2 shows emissions embodied in trade as a percentage share of total production-based emissions of the respective exporting region. While emissions embodied in exports from Non-OECD to OECD amounted to $51 \%$ of Non-OECD productionbased emissions in 2000, this number decreased to $36 \%$ in 2014. All the other trade flows-OECD to Non-OECD (13\% in 2000; $26 \%$ in 2014), as well as intra-regional trade in OECD (37\% in 2000; $42 \%$ in 2014$)$ and Non-OECD $(27 \%$ in $2000 ; 34 \%$ in 2014) - continue to gain importance even after the 2008-2009 period.

Finally, we consider the $\mathrm{CO}_{2}$ intensity of traded goods as an important indicator for the performance of carbon tariffs. Wood et al. (2019) show that $\mathrm{CO}_{2}$ intensity of trade from OECD to Non-OECD has been low and continues to decline. Moreover, $\mathrm{CO}_{2}$ intensity of trade from Non-OECD to OECD and intra Non-OECD has declined sharply between 1995 and 2015. Our MRIO analysis for EITE goods complements the findings of Wood et al. (2019) by showing the trends in $\mathrm{CO}_{2}$ intensity of average EITE production for both OECD and Non-OECD in Fig. 3. We find that while $\mathrm{CO}_{2}$ intensities in OECD and Non-OECD have declined substantially in the pre-crisis period and only slightly post-crisis, the ratio of $\mathrm{CO}_{2}$ intensities has remained rather stable over the whole period (2000-2014).

The development of $\mathrm{CO}_{2}$ intensities and emissions embodied in production and trade has direct implications for unilateral carbon pricing and the performance of carbon tariffs. The domestic - in our case OECD- $\mathrm{CO}_{2}$ intensity affects the $\mathrm{CO}_{2}$ price necessary to achieve a given emission reduction target. A higher foreign-in our case Non-OECD$\mathrm{CO}_{2}$ intensity implies not only a higher leakage rate induced by $\mathrm{OECD} \mathrm{CO}_{2}$ pricing standalone (i.e., without complementary tariffs), but also higher carbon tariffs rates to combat carbon leakage. Thus, the relative intensity levels between OECD and Non-OECD can affect the performance of carbon tariffs.

As to trade flows originating from Non-OECD, we expect opposing effects: increasing exports to OECD broaden the scope of carbon tariffs and thus enhance the potential for leakage reduction and burden shifting. At the same time, in the presence of growing dependence of OECD production processes on Non-OECD emission-intensive intermediate goods (see also Fig. 15), tariffs can even worsen the cost-disadvantage of individual 
Table 1 Model sectors and regions

\begin{tabular}{ll}
\hline Sectors and commodities & Countries and regions \\
\hline Energy sectors & OECD \\
Mining and quarrying & European Union (EU28) \\
Coke, refined petroleum and nuclear fuel & a \\
Electricity, gas and water supply $_{\text {Aggregated sectors }}$ & USA \\
EITE $^{\mathrm{b}}$ & Remaining OECD countries \\
All other industries and services & Non-OECD \\
& Russia \\
& India \\
\hline
\end{tabular}

${ }^{a}$ Included in the group of emission-intensive and trade-exposed industries (EITE).

${ }^{b}$ EITE_-energy-intensive and trade-exposed sectors: rubber and plastics; basic metals and fabricated metal; chemicals and chemical products; other non-metallic minerals; pulp, paper, and print

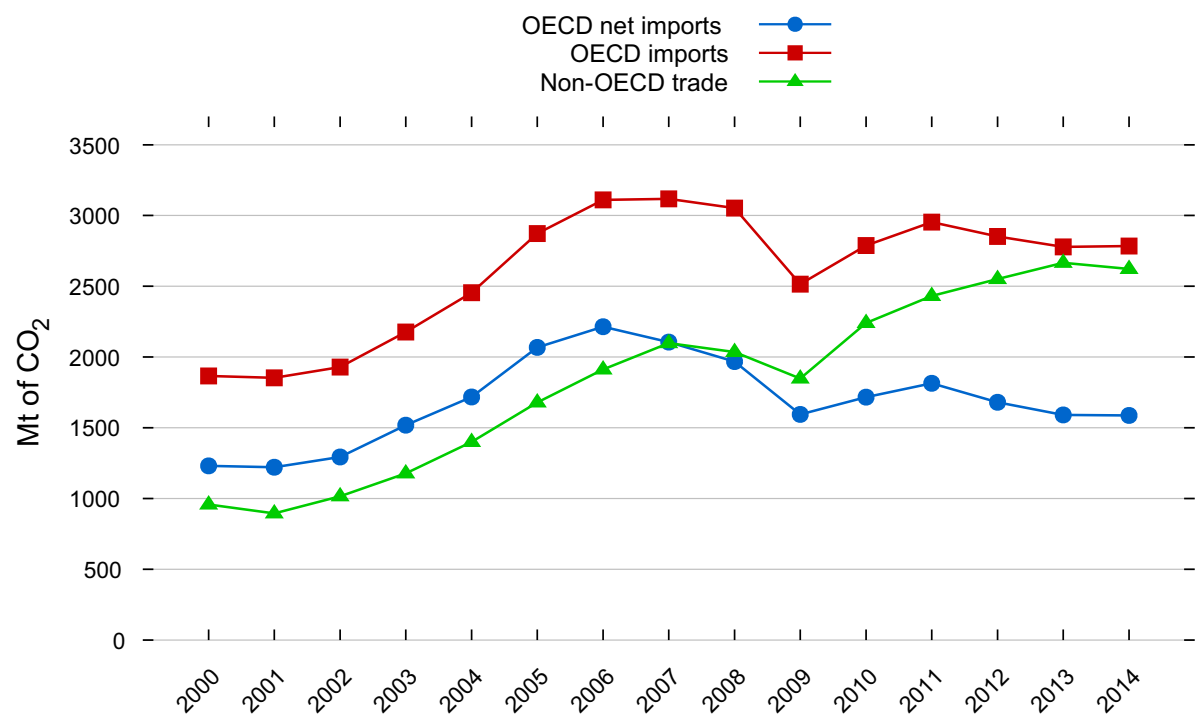

Fig. 1 Trade in embodied emissions. Note Embodied emissions refer to the entire $\mathrm{CO}_{2}$ emitted to produce and supply a certain good to the destination market, i.e., direct $\mathrm{CO}_{2}$ emissions from fossil fuel combustion in the production process as well as indirect $\mathrm{CO}_{2}$ emissions to produce intermediate inputs such as electricity and international transportation services

industries in OECD since imported intermediates become more expensive and (partly) increase leakage. ${ }^{14}$

14 This counterproductive effect of carbon tariffs is extensively studied in Böhringer et al. (2015). 


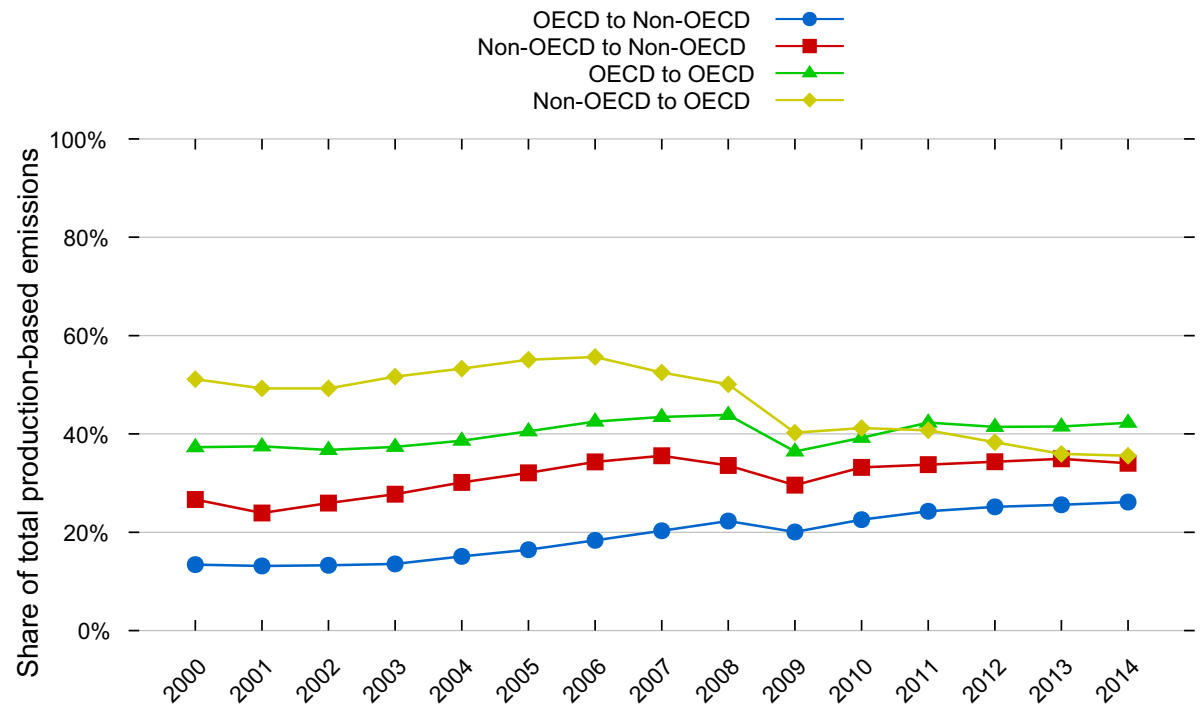

Fig. 2 Emissions embodied in trade as percentage share of total production-based emissions of exporting region. Note Embodied emissions refer to the entire $\mathrm{CO}_{2}$ emitted to produce and supply a certain good to the destination market, i.e., direct $\mathrm{CO}_{2}$ emissions from fossil fuel combustion in the production process as well as indirect $\mathrm{CO}_{2}$ emissions to produce intermediate inputs such as electricity and international transportation services

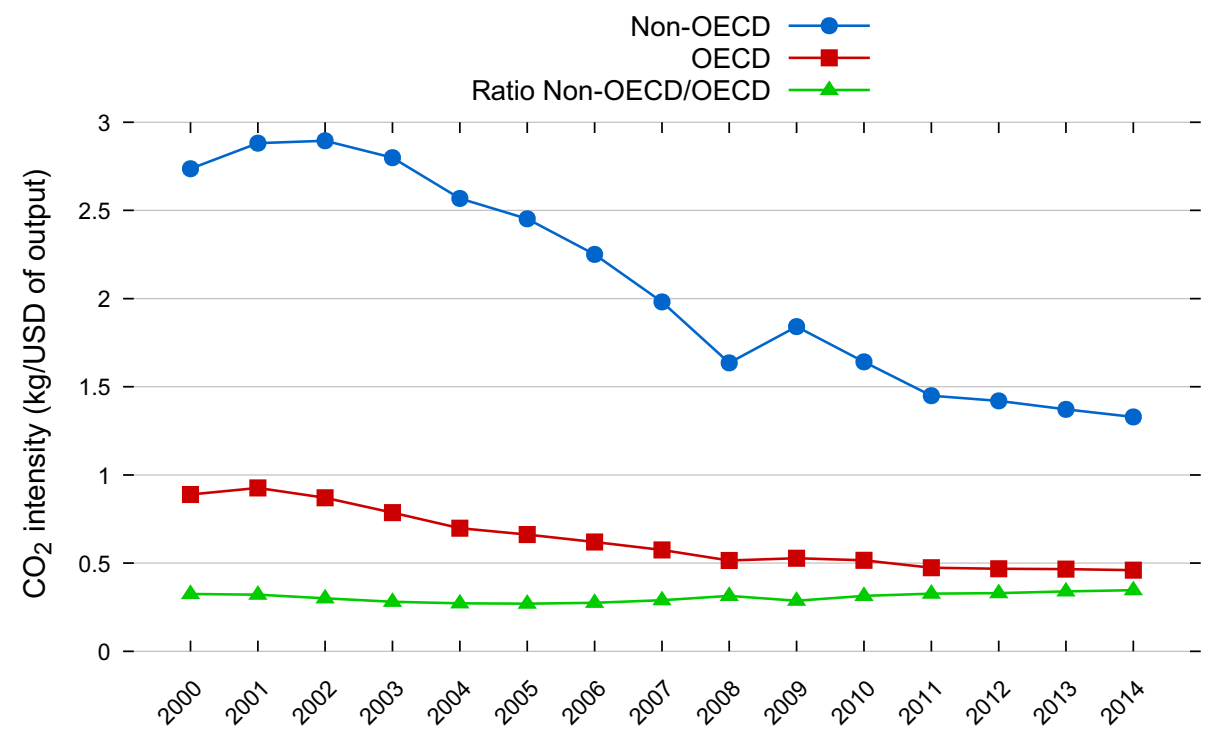

Fig. 3 OECD and Non-OECD $\mathrm{CO}_{2}$ intensity of EITE production

Notwithstanding, an increasing flow of emissions from OECD to Non-OECD countries is relevant for OECD's ability to pass-through costs under unilateral emission pricing stand-alone. This development, again, is countered by increasing Non-OECD trade 
integration. Increasing intra-Non-OECD trade facilitates the redirection of trade flows as a response to carbon tariffs. This phenomenon coupled with the decreasing share of production-based emissions embodied in exports from Non-OECD to OECD could then lead to tariffs becoming less effective in combating leakage and reducing the global cost of emission abatement.

\subsubsection{Structural Change}

Besides the changing patterns of trade in embodied emissions, structural change with respect to electricity usage and the composition of $\mathrm{CO}_{2}$ emissions in Non-OECD countries have implications on the performance of unilateral policies and carbon tariffs in particular. ${ }^{15}$ Electricity is a major source of emissions that is not internationally traded between Non-OECD and OECD countries in relevant quantities. That is, the Non-OECD electricity sector cannot be targeted by trade measures such as carbon tariffs directly but only indirectly through reduced demand for targeted exporting sectors.

Figure 4 shows the percentage decomposition of Non-OECD total $\mathrm{CO}_{2}$ emissions into emissions stemming from the electricity sector, the EITE industries, the rest of the economy (ROE), and final consumption. Total $\mathrm{CO}_{2}$ emissions from fossil fuel combustion in Non-OECD more than doubled from $9.7 \mathrm{Gt}$ in 2000 to almost $20.3 \mathrm{Gt}$ in 2014. While EITE sectors exhibit a slight increase in their share of the overall emissions (18\% in 2000; $21 \%$ in 2014), the share of emissions stemming from the electricity sector increased by 5 percentage points from about $41 \%$ in 2000 to $46 \%$ of total emissions in 2014 .

The decomposition of the $\mathrm{CO}_{2}$ intensity of Non-OECD EITE goods (see Fig. 5) indicates that the share of direct emissions has slightly decreased from about $31 \%$ in 2000 to $27 \%$ in $2014 .{ }^{16}$ At the same time, EITE industries' share of total electricity consumption in Non-OECD decreased from 19.6 in 2000 to $17.6 \%$ in 2014 (see Fig. 6). The results further show that electricity consumption in the Non-EITE industries (including the electricity sector itself) has increased (from 61 in 2000 to 69\% in 2014) compared to electricity consumption in the EITE sectors. Moreover, the electricity sector exhibits higher and sharper increasing cost shares of energy inputs - which point to higher energy demand - than EITE sectors (see Fig. 7).

The trends in the composition of $\mathrm{CO}_{2}$ emissions and electricity production imply that carbon tariffs might become less effective in reducing emissions in Non-OECD. While tariffs can only target traded goods directly, electricity as a non-traded good is gaining in relative importance. Non-OECD electricity markets are, in turn, affected through reduced demand from EITE sectors that are subjected to carbon tariffs. However, a substantial and increasing share of total electricity is rather consumed by Non-EITE sectors that are not subjected to tariffs. As a consequence, carbon tariffs may become less effective in targeting the major sources of emissions in Non-OECD production.

\footnotetext{
15 Note that developments in emissions trade and structural change regarding electricity and $\mathrm{CO}_{2}$ in production are obviously intertwined to some degree. If, for example, production becomes "cleaner", that would ceteris paribus also entail less emissions in trade. Nonetheless, we identify them as separate important drivers of our results.

${ }^{16}$ In the decomposition of the $\mathrm{CO}_{2}$ intensity, we distinguish between $\mathrm{CO}_{2}$ from fossil fuel combustion ("direct"), as well as $\mathrm{CO}_{2}$ from domestic and imported intermediate inputs ("indirect").
} 


\subsection{Computable General Equilibrium (CGE) Model}

We use a static computable general equilibrium (CGE) model to simulate the impacts of emission pricing and carbon tariffs. As we apply the CGE analysis to the benchmark data for each year between 2000 and 2014, we are able to quantify the efficacy of carbon tariffs in relation to the underlying changes in the data as discussed above in our MRIO analysis. CGE models are widely used for the economic impact assessment of policy initiatives as they capture price-driven supply and demand responses of economic agents in a comprehensive and consistent manner. Our analysis is based on a generic static CGE model of global production, consumption, and trade developed in Böhringer et al. (2018) — for a detailed algebraic summary of the model structure, see Appendix 4.

Primary factors in the model are labor, capital, and fossil resources. Capital and labor are intersectorally mobile. Fossil fuel resources are specific to the mining and quarrying sector in each region. Final consumption in each region is realized through a representative agent who receives income from the primary production factors and maximizes welfare subject to an income constraint.

Production of goods other than fossil fuels is captured through a three-level nested constant-elasticity-of-substitution (CES) function. At the top level, a material composite substitutes with a composite of value-added and energy. The second level describes the trade-off between value-added and energy. At the third level, labor and capital constitute the value-added composite. The energy goods-electricity, fossil resources, and refined oil products - also trade off in the energy aggregate at the same level. In the production of fossil fuels, the fuel-specific resource trades off with a Leontief composite of all other inputs. The top-level elasticity is calibrated to match an exogenous supply elasticity for fossil resources.

Final consumption is modeled through a representative agent in each region, who receives income from the primary factors and taxes. Government and investment demand are fixed at real base-year levels. Savings of the representative agent pay for investment while taxes pay for the provision of public goods and services. The representative agent maximizes her utility, given her remaining income based on a three-level CES function with the same characteristics as the production functions for goods other than fossil fuels.

International trade is modeled following Armington's differentiated goods approach, where goods are distinguished by origin (Armington 1969). The Armington composite for a traded good is a CES function of an imported composite and domestic production for that sector. The import composite in each country is again a CES function of production from all other countries. A balance of payment constraint fixes the base-year trade deficit or surplus for each region.

$\mathrm{CO}_{2}$ emissions are linked in fixed proportions to the use of fossil fuels. Restrictions on the use of $\mathrm{CO}_{2}$ emissions in production and consumption are implemented through exogenous emission constraints. $\mathrm{CO}_{2}$ emission abatement then takes place by fuel switching (inter-fuel substitution) or energy savings (either by fuel-non-fuel substitution or by a scale reduction of production and final demand activities).

For model parameterization, we follow the standard calibration procedure in applied general equilibrium analysis. Base-year input-output data together with exogenous estimates for elasticities determine the free parameters of the cost and expenditure functions such that the economic flows represented in the data are consistent with the optimizing behavior of the economic agents. The responses of agents to price changes 


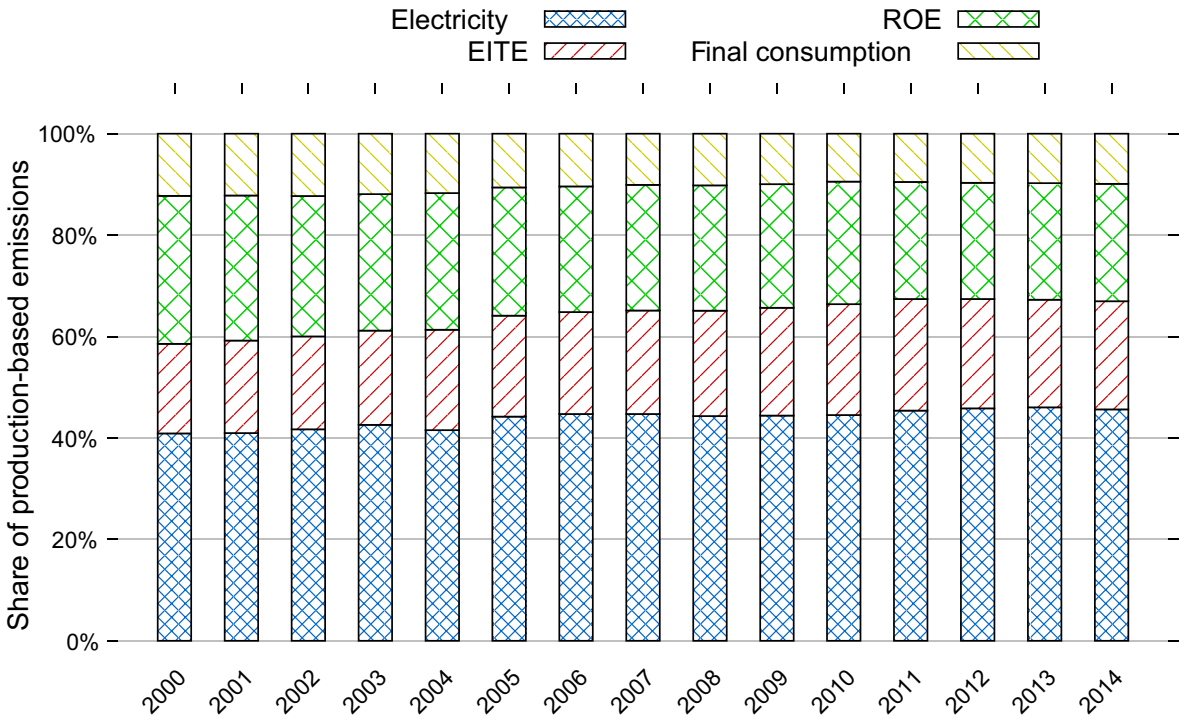

Fig. $4 \mathrm{CO}_{2}$ emissions in production and final consumption in Non-OECD. Note EITE-emission-intensive and trade-exposed sectors; ROE-rest of economy

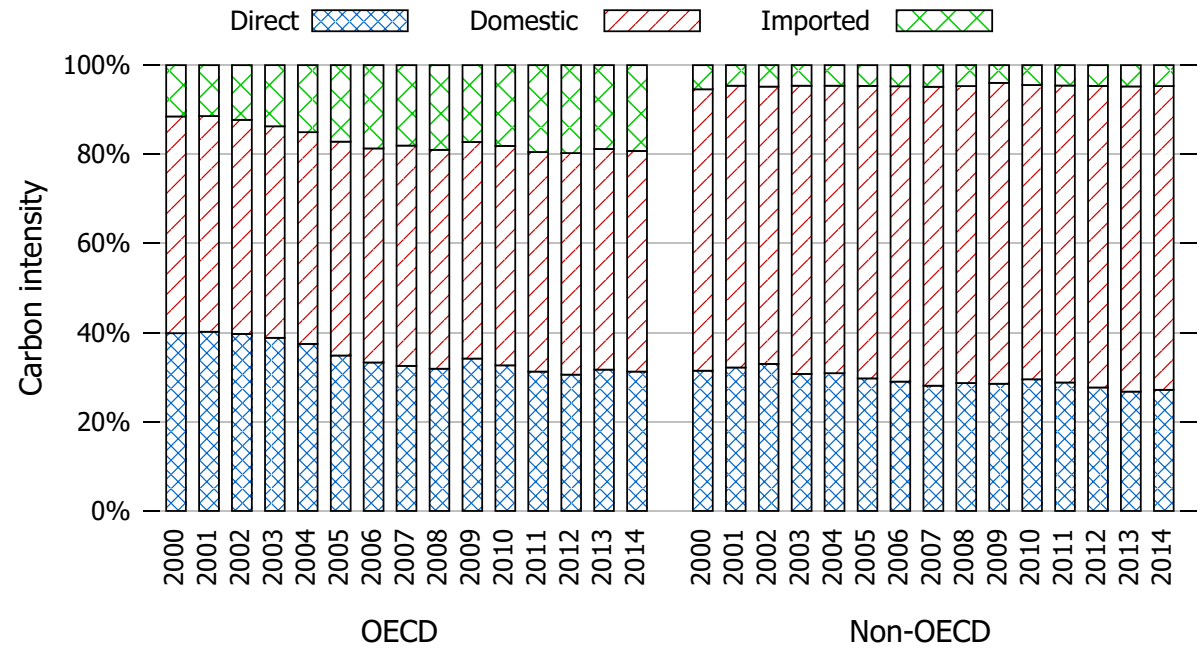

Fig. 5 Percentage decomposition of the $\mathrm{CO}_{2}$ intensity of an average EITE good in OECD and Non-OECD. Note Embodied emissions refer to the entire $\mathrm{CO}_{2}$ emitted to produce and supply a certain good to the destination market, i.e., direct $\mathrm{CO}_{2}$ emissions from fossil fuel combustion in the production process as well as indirect $\mathrm{CO}_{2}$ emissions to produce intermediate inputs such as electricity and international transportation services

are driven by a set of exogenous elasticities taken from the pertinent econometric literature. Sector-specific estimates based on WIOD data for cross-price elasticities of substitution between capital, labor, energy, and (non-energy) material inputs stem from Koesler and Schymura (2015). Trade elasticities are taken from the GTAP 9 database (Aguiar et al. 2016). The elasticities of substitution in fossil fuel production/cost 


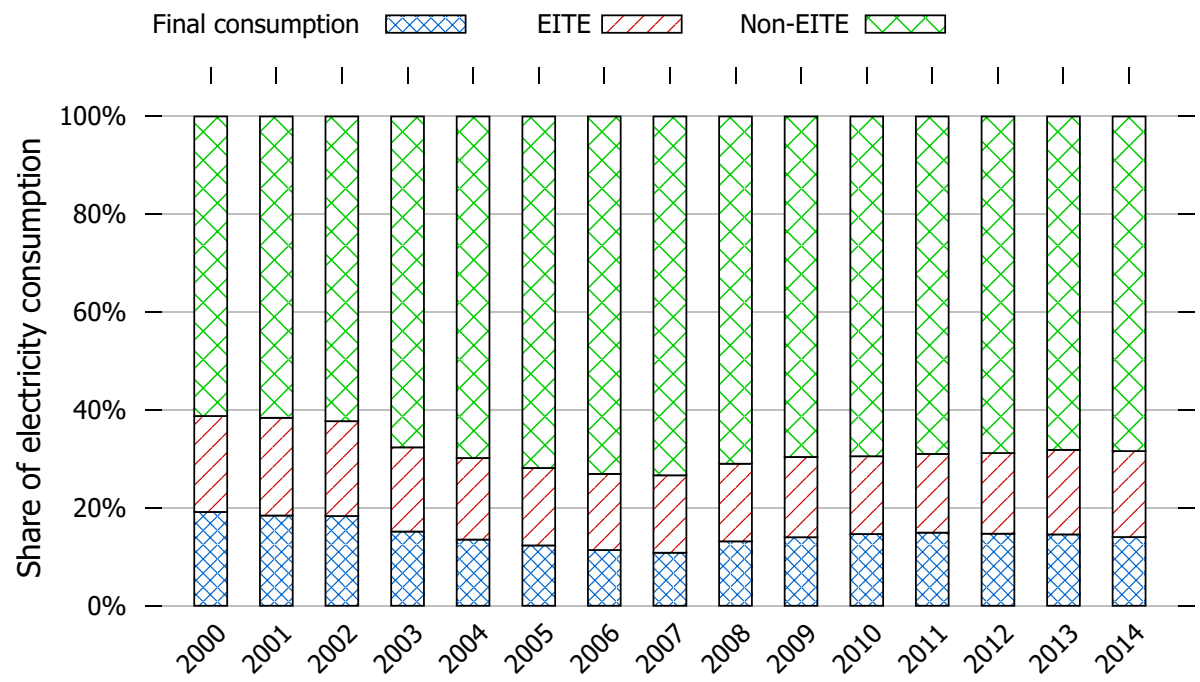

Fig. 6 Share of electricity consumption in Non-OECD

Energy Non-Energy 패

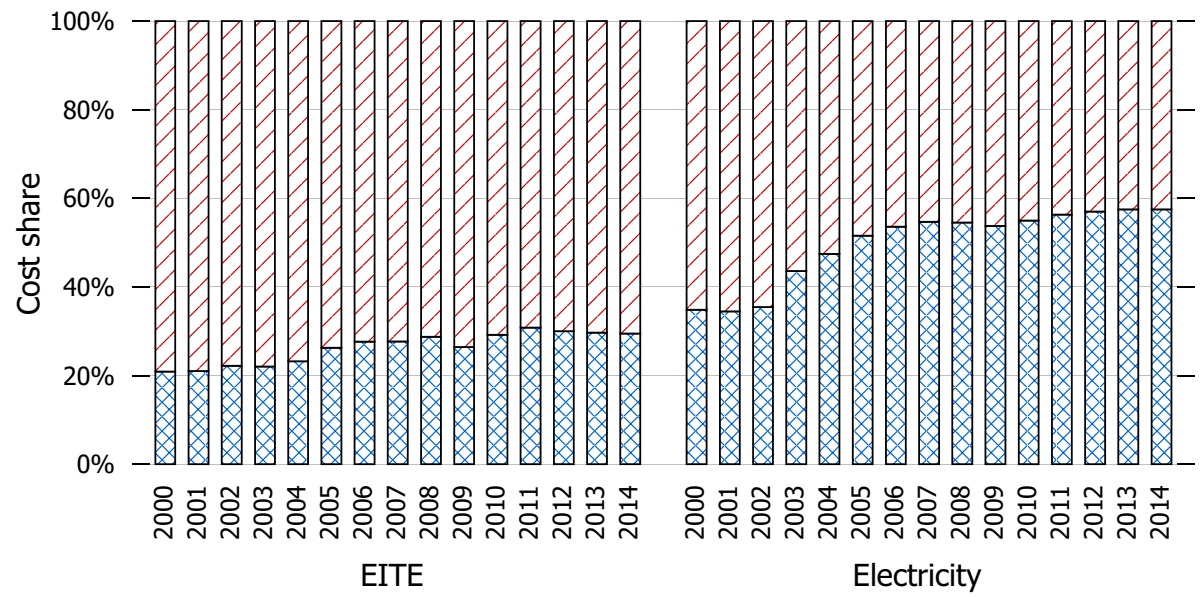

Fig. 7 Cost shares of energy and non-energy inputs in Non-OECD production in EITE and electricity sectors

functions are calibrated to match exogenous estimates of fossil-fuel supply elasticities (Graham et al. 1999; Krichene 2002; Ringlund et al. 2008). 


\section{Computable General Equilibrium Analysis}

\subsection{Policy Scenarios}

We simulate two alternative unilateral climate policy designs in OECD countries for each year under consideration (2000 to 2014). The first climate policy design is captured through the reference scenario REF where OECD countries jointly reduce domestic $\mathrm{CO}_{2}$ emissions by $20 \%$ compared to their benchmark emissions in the respective year. ${ }^{17}$ This is achieved through a uniform $\mathrm{CO}_{2}$ price within the OECD-implemented either as an OECD-wide emissions trading scheme or equivalently as a uniform OECD-wide $\mathrm{CO}_{2}$ tax. The second climate policy design is reflected in the TRF scenario where OECD countries also introduce a carbon tariff - a tariff on the imported embodied emissions at the $\mathrm{OECD} \mathrm{CO}_{2}$ price. In our central case simulations, the carbon tariff is levied on imports of emission-intensive and trade-exposed (EITE) goods.

To conduct a consistent global cost-effectiveness analysis, we keep the global level of emissions constant across REF and TRF scenarios for each year. This implies that the reduction target in the OECD as specified under REF must endogenously adjust in scenario TRF, such that the same level of global emissions is attained as in the respective REF case. ${ }^{18}$ By holding the level of global emissions constant across scenarios REF and TRF for each year, we circumvent an economic assessment of climate damages acknowledging larger uncertainties in external cost estimates of $\mathrm{CO}_{2}$ emissions.

Note that the benchmark data describes the business-as-usual situation in each year of our investigation period without further climate policies. The data capture developments in regional $\mathrm{CO}_{2}$ emissions and emission intensities. These developments are to some extent driven by emission pricing in individual OECD regions, but also by technological changes like shifts to unconventional gas or renewables, which e.g., led to substantial coal-gas substitution in the US (Feng et al. 2015; Kotchen and Mansur 2016). From an OECDwide perspective, actual emission pricing played a minor role in the period 2000-2014. For example, Bayer and Aklin (2020) find that the EU-ETS - by far the most relevant climate policy in terms of scope and stringency during the period under considerationsaved around 3.8\% of total EU-wide emissions in the period 2008-2016. Given that the EU accounts for about one-third of OECD's $\mathrm{CO}_{2}$ emissions, this amounts to roughly $1.3 \%$ of OECD-wide emissions. Thus, we refrain from explicitly incorporating climate policies across OECD countries into the original WIOD data.

\subsection{CGE Results}

The CGE analysis starts with the quantification of leakage rates triggered by the two alternative climate policy designs for each year between 2000 and 2014 (see Fig. 8). The leakage rate is defined as the increase in $\mathrm{CO}_{2}$ emissions in unregulated regions (here:

\footnotetext{
17 We opted for a fixed quantity target instead of a fixed price target for each year because it induces similar adjustment cost in OECD over the years and thus suits better as a reference to compare economic impacts. However, we include fixed $\mathrm{CO}_{2}$ taxes in our sensitivity analysis in Appendix 2.

18 Technically, this is implemented in the CGE model through an endogenous scaling of the OECD emission cap (or likewise the OECD emission price).
} 
Non-OECD regions) as a percentage share of the decrease in $\mathrm{CO}_{2}$ emissions in the regulated regions (here: OECD regions).

In the reference scenario (REF) where we consider uniform $\mathrm{CO}_{2}$ pricing stand-alone, we observe a steady increase in the leakage rate until the global financial crisis, from $7.5 \%$ in 2000 to $13.6 \%$ in 2008 . After the crisis, the leakage rate plateaus at a slightly lower level of $10-12 \%$. The overall development of the leakage rate in the REF case since 2000 is driven by two factors. First, the declining OECD share of global production-based $\mathrm{CO}_{2}$ emissions (57\% in 2000 and $37 \%$ in 2014). As the share of global $\mathrm{CO}_{2}$ emissions covered by unilateral OECD climate policies declines, the leakage rate goes up. ${ }^{19}$

Second, the $\mathrm{CO}_{2}$ intensity of EITE goods produced in OECD countries sharply decreases in the pre-crisis period and has plateaued in the post-crisis period (see Figs. 3 and 15). In absolute terms, the $\mathrm{CO}_{2}$ intensity of an average OECD EITE good decreases from $0.95 \mathrm{~kg} \mathrm{CO}_{2}$ per USD of EITE output in 2000 to 0.59 in 2014. The decline in direct and indirect domestic emissions indicates a trend towards "cleaner" domestic EITE production in the OECD. The lower the benchmark $\mathrm{CO}_{2}$ intensity, the higher must be the $\mathrm{CO}_{2}$ price to effect relative price changes sufficient to achieve a given emission reduction target. ${ }^{20}$ Along with higher unilateral $\mathrm{CO}_{2}$ prices, the leakage rate goes up. ${ }^{21}$

As expected, leakage rates under the carbon tariff regime (TRF) are lower in all years relative to the REF scenario. ${ }^{22}$ The reduction in the leakage rates due to carbon-based tariffs on EITE goods falls in the range of 4.8 and 10 percentage points. In absolute terms, the amount of abated $\mathrm{CO}_{2}$ emissions through tariffs in Non-OECD increases over the period. In relative terms, which we define as the share of leakage in the reference scenario that can be eliminated through tariffs, we find that the REF leakage rate is reduced between 64 and $81 \%$ - with a mean reduction of $69 \%$.

As illustrated in Fig. 8, the potency of carbon tariffs in combating leakage increases from 2001 and reaches its peak level in 2006, which is precisely the period where trade in emissions from Non-OECD to OECD also increases in relative terms (see Fig. 2). During the crisis, the effectiveness of tariffs decreased by more than 20 percentage points when trade slowed considerably. Leakage reduction through tariffs plateaus after 2011 following a 10-percentage point increase between 2009 and 2011. The leakage reduction potential of carbon tariffs remains on a relatively high level, and the evolution mirrors the trends we observe for OECD total imports of embodied emissions. That is, the effectiveness of tariffs to combat leakage correlates positively with embodied emissions flowing from Non-OECD to OECD countries.

In the years where the financial crisis depresses trade in emissions, the effectiveness of tariffs in combating leakage is negatively impacted, and when trade in emissions plateaus, leakage reduction through tariffs also plateaus. The developments of $\mathrm{CO}_{2}$ intensities

\footnotetext{
19 This result has been established in Böhringer et al. (2014) who show analytically that ceteris paribus emission leakage goes up as the share of base-year emissions in the abatement coalition over global emissions declines.

20 The emission price in scenario REF increases from 49 USD to 80 USD per ton of $\mathrm{CO}_{2}$ over time, plateauing in the post-crisis period. The emission price in scenario TRF is slightly below the REF price for each year (see Fig. 16).

21 In order to disentangle effects from increasing $\mathrm{CO}_{2}$ prices, we consider a scenario with fixed (deflated) $\mathrm{CO}_{2}$ prices rather than fixed reduction targets in our sensitivity analysis. Our main insights remain robust.

22 As a consequence of leakage reduction, $\mathrm{CO}_{2}$ emission prices in TRF are lower than in REF. The reason is that lower leakage rates in TRF imply a lower effective domestic emission reduction requirement for OECD to achieve the same global emission reduction as in REF.
} 


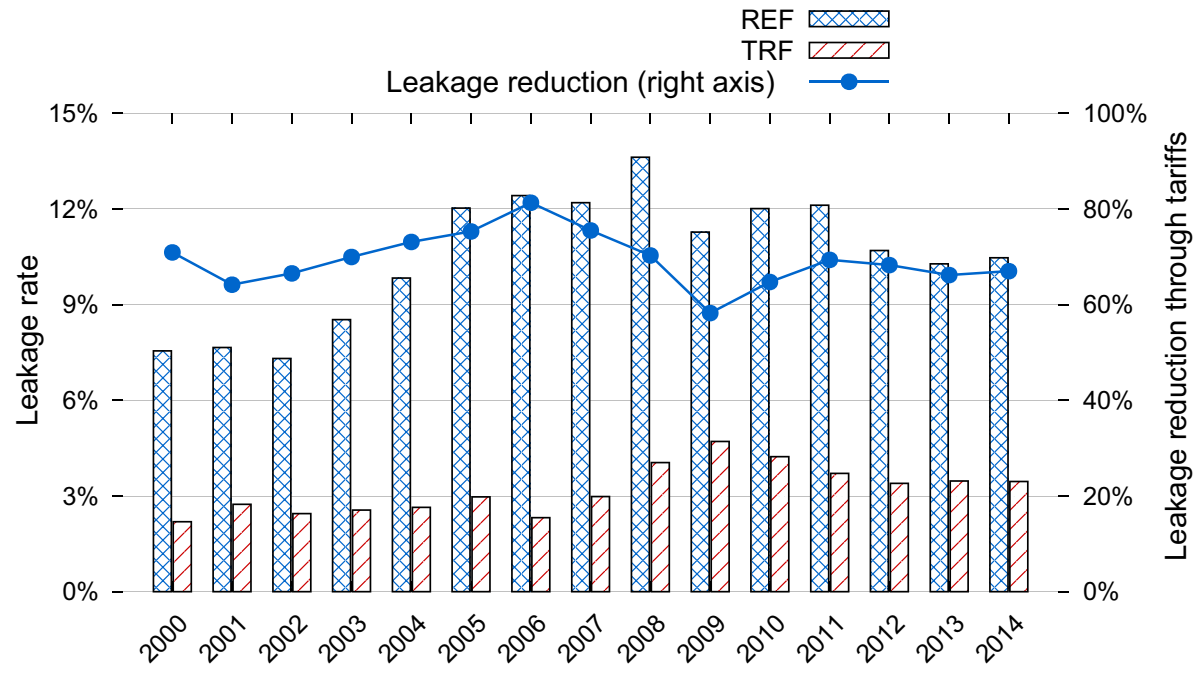

Fig. 8 Leakage rates under REF and TRF (left axis) and percentage leakage reduction through tariffs (right axis)

in EITE production in OECD and Non-OECD have opposing effects on the performance of carbon tariffs in leakage reduction. As argued above, a lower OECD $\mathrm{CO}_{2}$ intensity implies a higher leakage rate without tariffs and thereby a higher potential for leakage reduction. A lower Non-OECD $\mathrm{CO}_{2}$ intensity, on the other hand, implies lower endogenous tariff rates at the border, reducing the leakage reduction potential of tariffs. As illustrated in Fig. 3, the ratio of $\mathrm{CO}_{2}$ intensities of Non-OECD and OECD EITE production remains roughly stable across our different base years, suggesting that the two effects level out to a large extent.

However, there are two additional underlying factors laid out in the MRIO analysis that limit the effectiveness of carbon tariffs in reducing leakage: First, not only do we observe more trade integration between OECD and Non-OECD over the years, but also more trade integration among Non-OECD economies. Consequently, supply can more easily be redirected within Non-OECD when a carbon tariff is introduced in OECD countries. This evasion mechanism becomes evident from Fig. 9, which reports the additional emissions trade among Non-OECD countries in response to unilateral OECD climate policies as a percentage share of OECD emission reduction. Keeping in mind the increase in business-asusual intra-Non-OECD emissions trade (see Fig. 1), we find that a uniform OECD-wide $\mathrm{CO}_{2}$ pricing (REF) induces an expansion of intra-Non-OECD emissions trade from 0.94 in 2000 to $2.2 \%$ in 2014, while with additional carbon tariffs (TRF) we find an expansion from 2.3 in 2000 to $4.2 \%$ in 2014 compared to the emission reduction in OECD under REF and TRF, respectively.

Second, Non-OECD economies have undergone structural change towards increased electrification, while at the same time, the EITE share of total electricity consumption has slightly declined (see Fig. 6). Figure 10 provides a decomposition of the leakage rates into Non-OECD emission changes in the electricity sector, the EITE sector, and the rest of the economy (ROE). In the REF scenario, EITE leakage lies between 2.5 and $5 \%$ and is driven by $\mathrm{CO}_{2}$ prices. However, carbon tariffs are able to shut down the competitiveness channel such that the negative demand shock through tariffs leads to negative leakage in EITE sectors. Without the development of enhanced intra Non-OECD trade in embodied emissions 


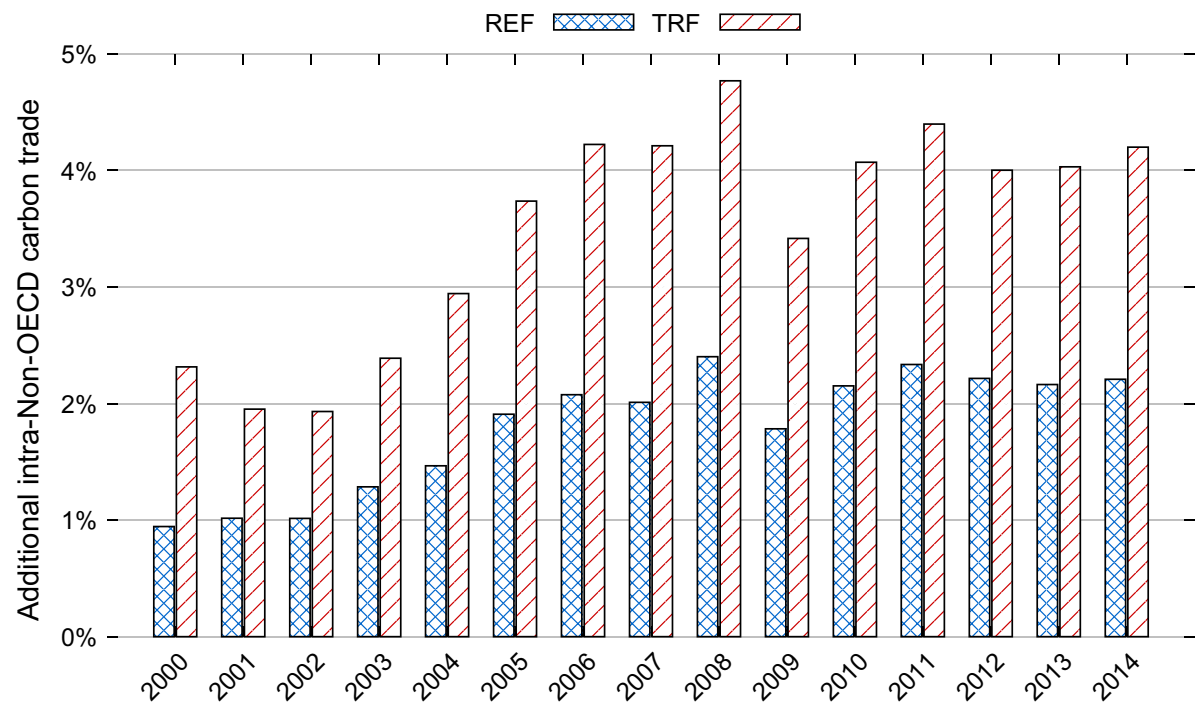

Fig. 9 Additional intra-Non-OECD trade in embodied emissions under REF and TRF as a percentage of emission reduction in OECD countries

described in Sect. 2.2 above, EITE leakage would be reduced even further due to increasing $\mathrm{CO}_{2}$ emission prices in OECD.

On the other hand, electricity leakage is mainly a manifestation of leakage through the fossil fuel channel: As fossil fuel prices decline due to climate policies, electricity production and consumption in Non-OECD go up. Under REF electricity leakage increases and ranges between 4.2 and $8.1 \%$ over the period. This is driven by a structural change towards higher energy demand in Non-OECD electricity production. Even under TRF, electricity leakage still increases from 2.7 in 2000 to $3.8 \%$ in 2014. The attenuation of fossil-fuelchannel leakage through carbon tariffs, thus, becomes less effective over the years.

The ineffectiveness of tariffs in combating leakage through the fossil-fuel channel is because tariffs are unable to attenuate the effects of declining international energy prices. At the same time, the electricity sector exhibits higher and increasing cost shares of energy inputs than the EITE sectors covered under tariffs (see Fig. 7). Thus, as the share of the electricity sector's emissions increases over time due to an increasing share of Non-EITE sectors electricity consumption (see the discussion as to Fig. 4), the electricity sector is less affected by carbon tariffs. ${ }^{23}$ Overall, the effectiveness of carbon tariffs to combat leakage is hampered due to the increasing importance of the fossil-fuel price channel.

Global cost-effectiveness of unilateral OECD $\mathrm{CO}_{2}$ emission pricing is only slightly improved when accompanied by additional carbon-based tariffs on EITE imports. ${ }^{24}$ It should be kept in mind that emission regulation in our cost-effectiveness approach

\footnotetext{
23 In the sensitivity analysis in Appendix 2, we find that this still holds if the tariff is expanded to all sectors of the economy. Still, there is a slight shift of electricity consumption from trade-exposed sectors towards sectors serving the domestic market, making electricity sector emissions less accessible for carbon tariffs.

24 Throughout our CGE analysis, we measure economic adjustment cost to emission regulation as Hicksian equivalent variation in percentage share of the business-as-usual income for the respective base year.
} 


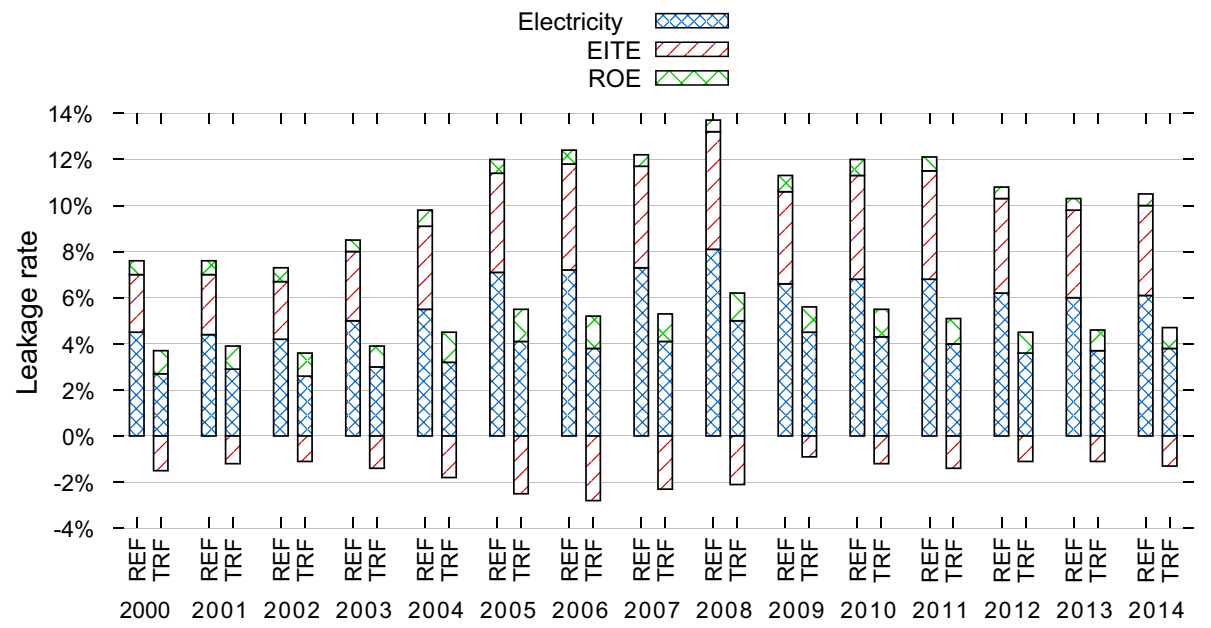

Fig. 10 Leakage rates under REF and TRF decomposed into Non-OECD emission changes in the electricity sector, the EITE sector, and the rest of economy (ROE)

generally induces positive cost since we do not monetize the benefits from emission reductions. Figure 11 indicates that global economic cost in the REF scenario ranges between 0.12 and $0.20 \%$ of the global business-as-usual income. ${ }^{25}$ The development of cost across the different base-years mirrors the decreasing trend in $\mathrm{CO}_{2}$ intensity of average EITE products in the OECD (see Figs. 3 and 15).

With a constant reduction target, a lower $\mathrm{CO}_{2}$ intensity requires higher $\mathrm{CO}_{2}$ prices (taxes), which — absent from external cost accounting - lead to higher losses in allocative efficiency. On average, the imposition of carbon tariffs reduces global economic adjustment cost under REF by $4.5 \%$. The limited scope of carbon tariffs for improving global cost-effectiveness of unilateral emission pricing echoes caveats on carbon-based import tariff applied as the industry-average. Since this does not reflect firm-specific heterogeneities, it fails to incentivize the deployment of less emission-intensive technologies in unregulated regions (Böhringer et al. 2017). This is a common finding in the applied literature on border carbon adjustments and has been indicated by other authors (e.g. Böhringer et al. 2012; Branger and Quirion 2014).

With respect to burden-sharing of the global adjustment cost, Fig. 12 shows that the economic burden of emission reduction in OECD can be shifted to Non-OECD countries. Even under the reference scenario (REF), unilateral OECD emission pricing to cut OECD $\mathrm{CO}_{2}$ emissions by $20 \%$ induces a substantial burden to Non-OECD countries. Although the $\mathrm{CO}_{2}$ price in OECD rises from 49 USD in 2000 to 80 USD in 2014 (see Fig. 16), the adjustment cost in OECD is relatively stable over the years (ranging between 0.1 and $0.16 \%$ of business-as-usual income), while Non-OECD countries face higher cost, particularly in the pre-crisis period (between 0.13 and $0.36 \%$ ). This partly reflects the finding of increasing shares of production-based emissions that OECD countries export to Non-OECD (see Fig. 2), allowing for cost pass-through to a greater extent. In the post-crisis period, the incidence on Non-OECD remains on a lower level and even declines towards the current

${ }^{25}$ Global welfare accounting is based on a utilitarian (Benthamite) perspective. 


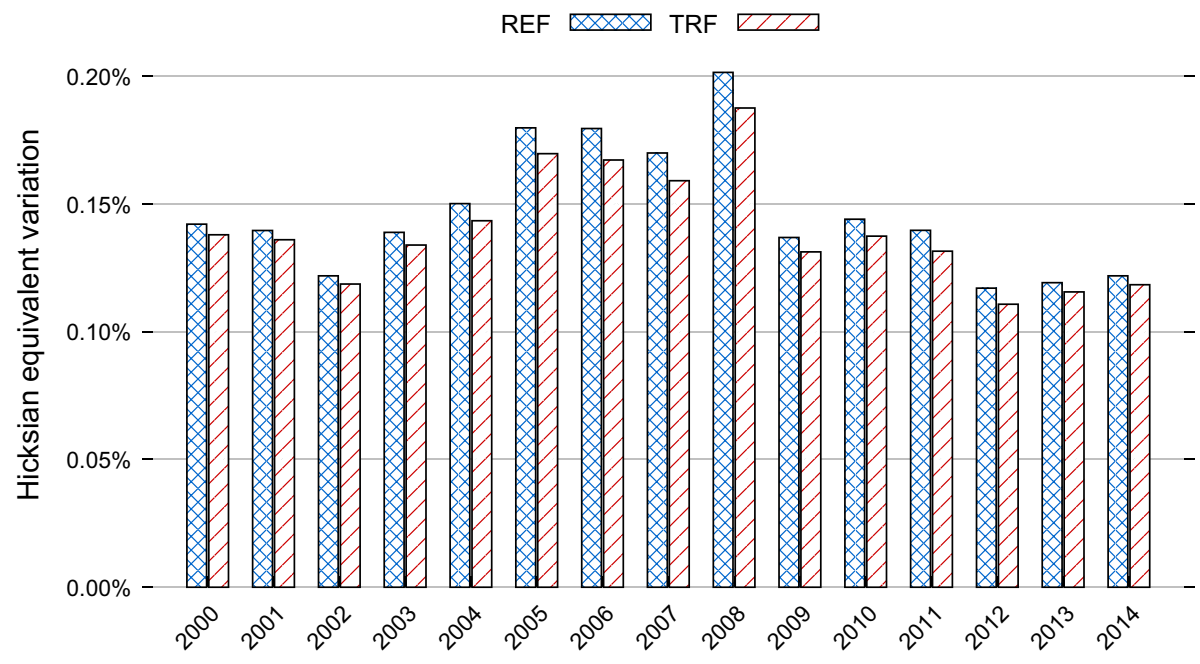

Fig. 11 Global economic cost under REF and TRF. Note Costs are reported as Hicksian equivalent variation as a percentage share of business-as-usual income

edge. The markedly reduced spillover effect in the post-crisis period reflects the decline of the relative importance of trade with OECD countries.

Supplementary carbon tariffs on EITE imports from Non-OECD further amplify the incidence of OECD emission abatement on Non-OECD countries such that Non-OECD countries assume a significantly larger share of the global cost. With a carbon tariff in place, we observe relatively small income losses for the OECD while a substantial and increasing share of the emission abatement burden is shifted to Non-OECD countries. Note that the adverse economic effects of tariffs after the financial crisis (2009-2014) are still high for Non-OECD countries compared to REF, albeit on lower levels than in the precrisis period.

Figure 13 further illustrates the burden-sharing of unilateral OECD emission reduction costs by using an additional indicator. We define the burden-sharing ratio as the ratio of welfare indexes, i.e., OECD welfare over Non-OECD welfare indexed to their respective business-as-usual welfare. ${ }^{26}$ In the reference case (REF), the burden-sharing ratio is above the level of 1 for all years except 2013-2014, meaning that Non-OECD countries suffer more than OECD countries in relative terms. The indicator shows a sharp increase in the pre-crisis period, mirroring the increase in the relative importance of the trade flow from OECD and Non-OECD. On the other hand, the post-crisis period is characterized by a decline in the relative importance of trade between OECD and Non-OECD. Here, the OECD bears larger parts of the burden, and in 2013 and 2014, the ratio even falls below 1 . Carbon tariffs (TRF) exacerbate these effects: When the burden-sharing ratio rises under $\mathrm{REF}$, it rises even steeper under TRF; when the ratio declines under REF, it declines more under TRF.

\footnotetext{
${ }^{26}$ For example, a burden-sharing ratio value of 2 would indicate that in the counterfactual OECD's welfare index is twice as high as Non-OECD's welfare index, where each index is scaled to unity in the business-asusual.
} 


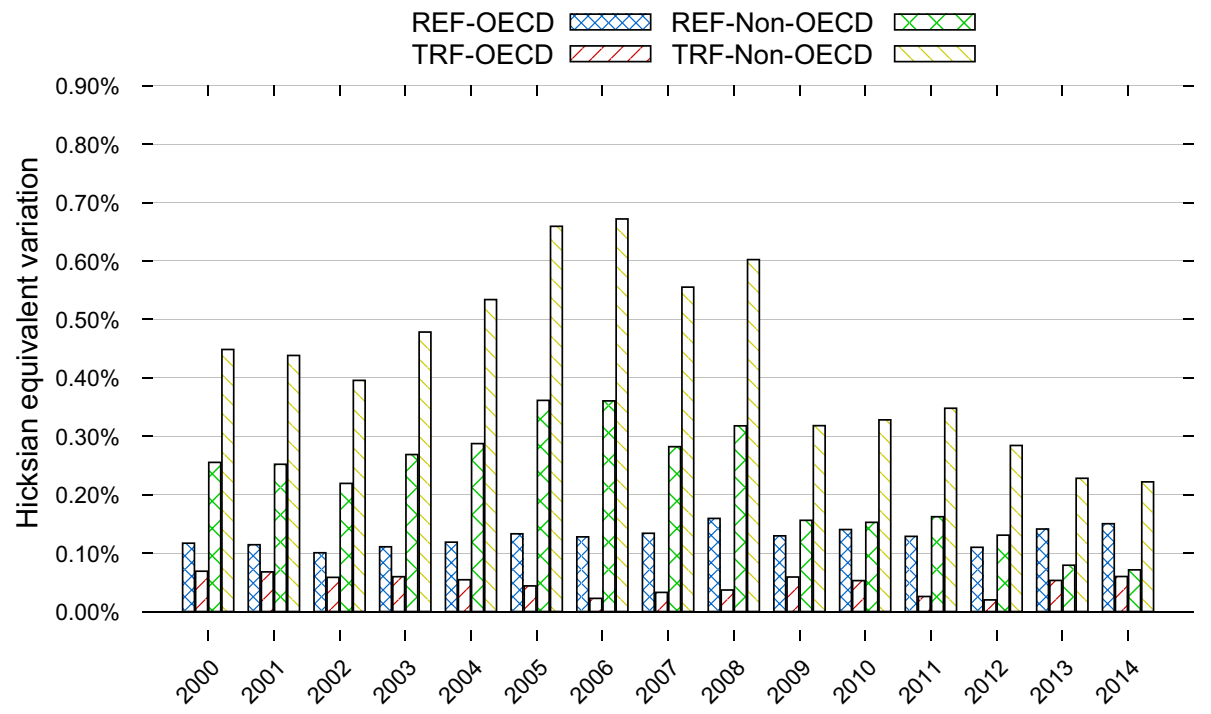

Fig. 12 Economic adjustment cost in OECD and Non-OECD under REF and TRF. Note Costs are reported as Hicksian equivalent variation as a percentage share of business-as-usual income

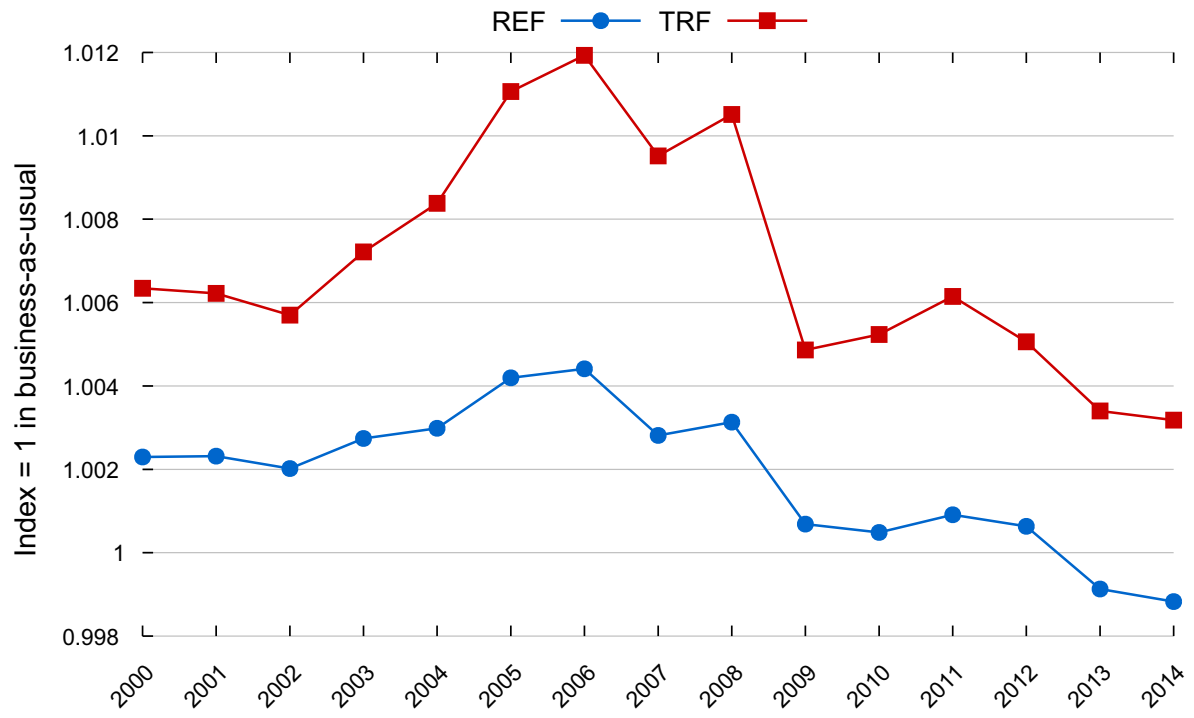

Fig. 13 Burden sharing (BSR) between OECD and Non-OECD under REF and TRF. Note The burden sharing ratio shows the ratio of welfare indexes, that is, OECD welfare indexed to business-as-usual welfare over Non-OECD welfare indexed to their respective business-as-usual welfare

The rationale behind the burden-shifting effect of unilateral OECD emission pricing is as follows. Emission pricing affects the terms of trade, i.e., the ratio of export prices to import prices for OECD and Non-OECD countries. The heterogeneous nature (imperfect substitutability) of traded commodities makes it possible for an open economy to pass on 


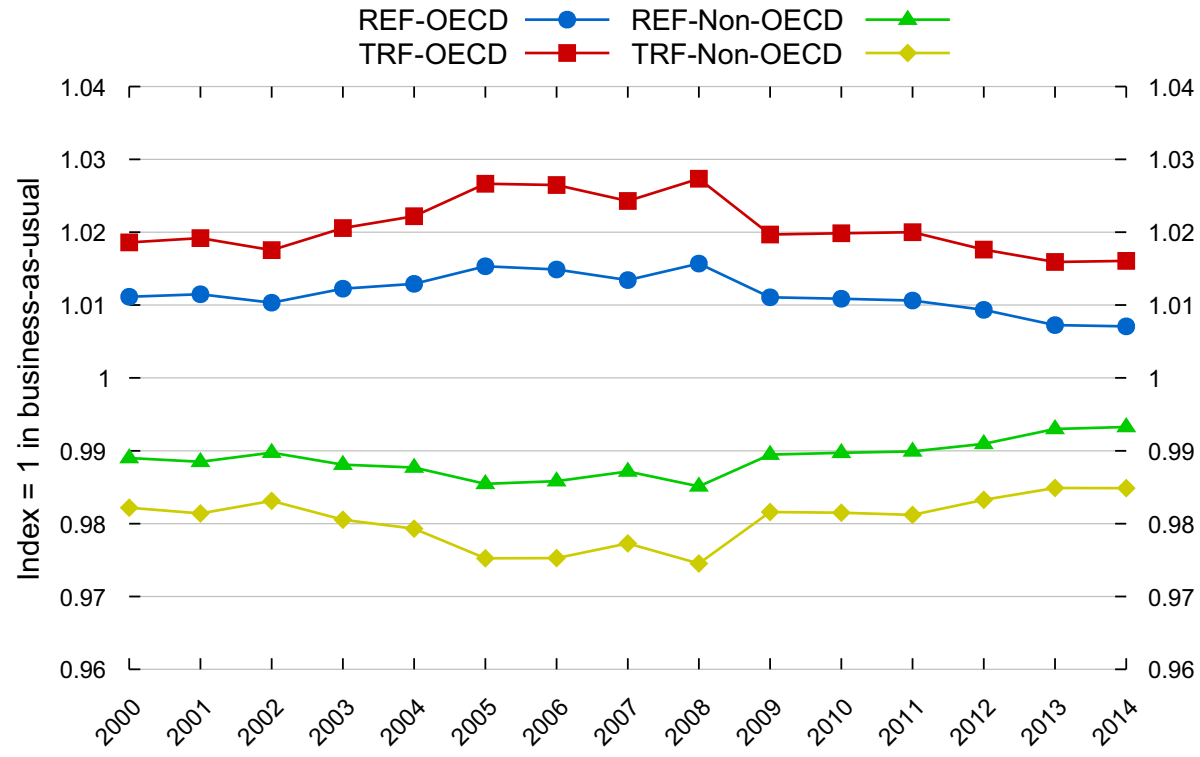

Fig. 14 Terms of trade for OECD and Non-OECD under REF and TRF. Note The index shows the ratio of the Fisher price indexes for exports and imports in OECD and Non-OECD

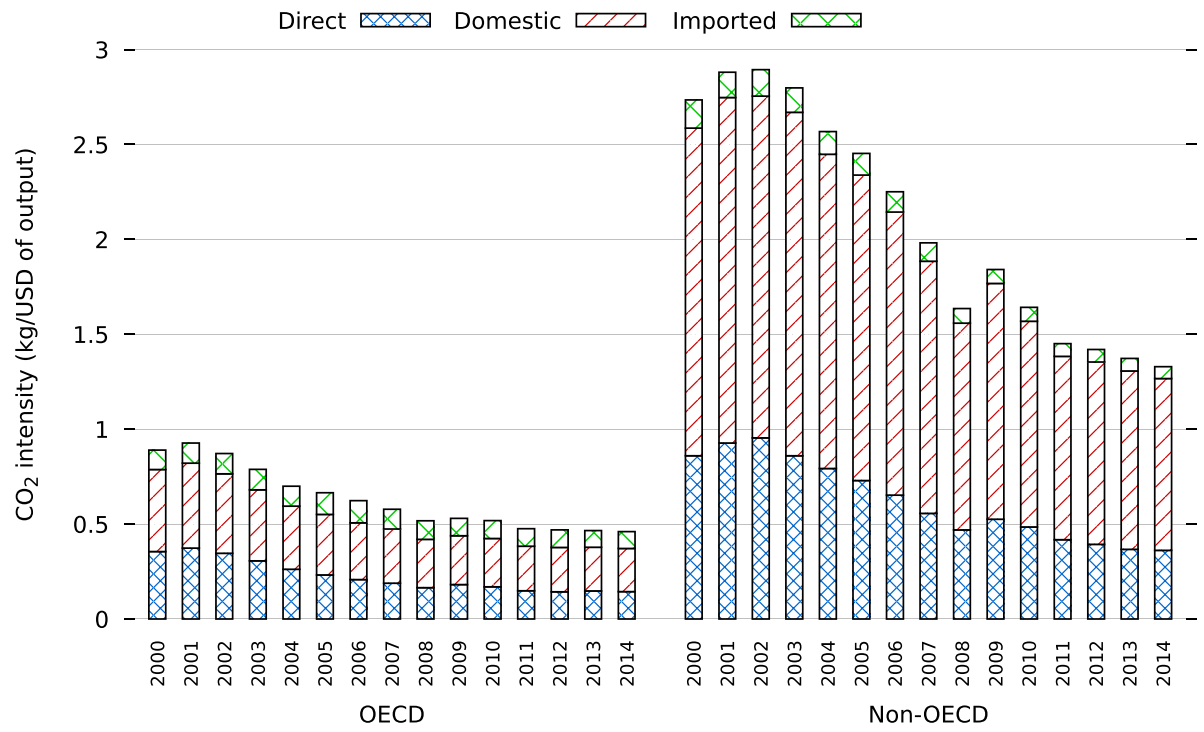

Fig. 15 Decomposition of the $\mathrm{CO}_{2}$ intensity of an average EITE good in OECD and Non-OECD. Note Embodied emissions refer to the entire $\mathrm{CO}_{2}$ emitted to produce and supply a certain good to the destination market, i.e., direct $\mathrm{CO}_{2}$ emissions from fossil fuel combustion in the production process as well as indirect $\mathrm{CO}_{2}$ emissions to produce intermediate inputs such as electricity and international transportation services

a fraction of domestic abatement cost via higher prices to trading partners. In this vein, carbon tariffs may work as a strategic substitute for "optimal" tariffs-where "optimal" is defined from the perspective of the tariff imposing country that seeks to exploit terms of 


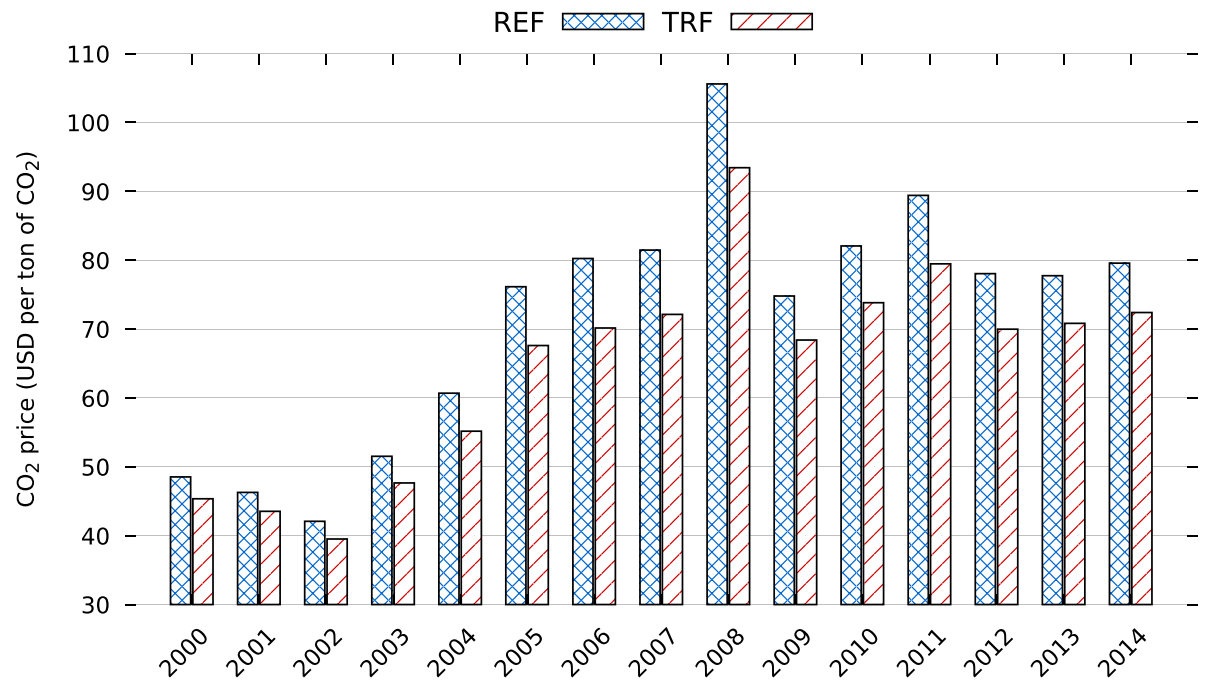

Fig. $16 \mathrm{CO}_{2}$ prices under REF and TRF

trade. In fact, the adverse terms-of-trade effects for Non-OECD countries become more pronounced with carbon-based import tariffs to the extent that the effective price increase is still below an optimal tariff rate.

Figure 14 shows the development of the terms of trade effect - the Fisher-price indexas the main driver of the burden-sharing described above. ${ }^{27}$ Higher domestic OECD $\mathrm{CO}_{2}$ price (see Fig. 16) - due to a decreasing $\mathrm{CO}_{2}$ intensity of OECD EITE production (see Fig. 15) - combined with more trade flows from OECD to Non-OECD induce stronger terms of trade effects that work in favor of OECD and to the disadvantage of Non-OECD countries. After the 2007-2008 financial crisis, the terms of trade deteriorated and slightly declined for OECD countries. Inversely, the terms of trade improve for Non-OECD countries. The terms of trade effects are further amplified through carbon-based tariffs exhibiting the same pattern as the burden-sharing ratio: The movements of the index under REF become even steeper under TRF.

\subsection{Sensitivity Analysis}

We conduct sensitivity analysis to assess the robustness of results to key assumptions underlying our core simulations. Firstly, we investigate the influence of trade elasticities and fossil fuel supply elasticities, which are known as critical parameters in climate policy impact assessment. Secondly, we vary the design of unilateral climate policy along the following dimensions: (1) fixed $\mathrm{CO}_{2}$ tax instead of quantity target, (2) the stringency of the reduction target, (3) coalition size, and (4) the introduction of carbon-based rebates to exports in addition to carbon-based tariffs on imports.

\footnotetext{
27 The Fisher index is the geometric mean of the Laspeyres index and Paasche index. The Laspeyres index uses benchmark quantities, whereas the Paasche index uses counterfactual quantities to calculate aggregate price changes. Both indexes entail substitution-biases which the Fisher index overcomes (Reinsdorf 2010).
} 
We find that our main insights remain robust to these changes in the parametrization space: Carbon tariffs can attenuate leakage substantially, and in particular, can shut down the competitiveness channel for leakage. The effectiveness of tariffs in reducing leakage correlates positively and strongly with the relative importance of taxed trade flows and is hampered by structural change towards electricity in the taxed region. The impact of tariffs on global cost-effectiveness is rather modest. The high potency of carbon tariffs in shifting the burden of abatement from regulating OECD countries to Non-OECD trading partners without emission regulation via changes in the terms of trade, on the other hand, persists and increases markedly in the pre-crisis period. In the post-crisis period, it declines. Details of the sensitivity analysis are shown in Appendix 2.

\section{Conclusion}

At the 21st Conference of Parties to the United Framework Convention on Climate Change in Paris, 195 countries agreed to reduce their carbon output "as soon as possible" in order to keep global warming "to well below $2{ }^{\circ} \mathrm{C}$ " (UNFCCC 2015). Despite this Paris Agreement, the world community is still far off from uniform and stringent emission pricing as the first best strategy to combat global warming. It seems likely that industrialized countries will go ahead with stringent emission pricing in the mid-run, whereas developing countries adopt rather lenient regulations. Major discrepancies in the stringency of emission pricing across trading partners raise concerns on carbon leakage and the global costeffectiveness of more ambitious climate action in OECD countries.

Against this background, carbon tariffs are discussed as a complementary instrument to unilateral emission pricing. Carbon tariffs tax the carbon emissions embodied in imported goods and thereby extend the reach of domestic emission pricing. Previous empirical analysis on the impacts of carbon tariffs has identified that carbon tariffs can substantially reduce leakage but deliver only small gains in global cost-effectiveness while amplifying the burden-shifting effect of carbon pricing from developed OECD countries to developing non-OECD countries. However, such analysis has been based on a single observation of global economic activity in time.

In this paper, we have investigated the environmental and economic implications of carbon tariffs as the structure of international trade, and national production and consumption patterns change over time. The motivation for our analysis stems from the fact that trade in emissions embodied in goods has sharply increased until the financial crisis of 2007-2008 and plateaued afterward. Intuitively, one would expect that the potency of carbon tariffs to reduce leakage and improve the global cost-effectiveness of unilateral emission pricing will increase with more carbon embodied in trade.

Our assessment of carbon tariffs using data from 2000 and 2014 shows that in addition to the amount and intensity of emissions embodied in trade, the main determinants of the effectiveness of carbon tariffs are the relative importance of trade flows as well as structural changes in the targeted economies that can make emissions less accessible for tariffs. We find that the gradual redirection of emission-intensive trade away from OECD to within Non-OECD countries limits the reach of carbon tariffs imposed by OECD countries. Furthermore, changes in Non-OECD electricity usage and the composition of $\mathrm{CO}_{2}$ emissions decrease incentives to reduce emissions as a reaction to carbon tariffs.

Our results confirm that the potential of carbon tariffs to improve the global cost-effectiveness of unilateral climate policy remains rather modest. In contrast the burden-shifting 
potential of carbon tariffs from abating industrialized OECD regions to developing NonOECD countries increases markedly between 2000 and 2008 and declines after the financial crisis. Again, the main drivers behind are the relative importance of trade flows as well as a structural change towards more electricity.

Our analysis is meant to set the political discussion of carbon tariffs on more informed grounds. From a policy perspective, our assessment shows that the case for carbon tariffs concerning leakage reduction becomes stronger in periods where the targeted trade flow gains in relative importance, which has not been the case for trade from Non-OECD to OECD after the 2007-2008 financial crisis. The global cost-effectiveness argument in favor of carbon tariffs does not gain weight during the period of investigation (2000-2014). The burden-shifting potential of carbon tariffs from abating industrialized regions to nonabating developing countries persists as a critical policy caveat.

\section{Appendix 1: Supplementary results}

Similar to Figs. 5, 15 decomposes embodied $\mathrm{CO}_{2}$ intensity for an average EITE good in OECD and Non-OECD in absolute terms. The label "Direct" refers to direct emissions from fossil fuel combustion in the production process, the label "Domestic" to indirect emissions from emissions embodied in domestic intermediate inputs, and the label "Imported" to indirect emissions from emissions embodied in imported intermediate inputs (including emissions from associated international transport services). It becomes apparent that while the share of direct and domestic emissions dominate, the share of embodied emissions in the average OECD EITE good stemming from imported non-OECD sources almost doubled from 11 in 2000 to $19 \%$ in 2014. This has two opposing implications for the effectiveness of tariffs in the competitiveness channel: on the one hand, more embodied emissions can be taxed at the border, which puts increasing downward pressure on demand for imports. On the other hand, domestic EITE production faces a further cost-disadvantage on foreign markets since imported intermediates become more expensive. ${ }^{28}$

\section{Appendix 2: Sensitivity Analysis}

The sensitivity analysis is organized into two parts. In the first part (Appendix 2.1), we assess the implications of changes in trade and fossil fuel supply elasticities, which stand out for their critical importance to the magnitude of carbon leakage and terms-of-trade effects. In the second part (Appendix 2.2), we alter assumptions on unilateral climate policy design. Specifically, we consider a fixed $\mathrm{CO}_{2}$ tax instead of a quantity target, vary the emission reduction target, coalition size, and the comprehensiveness of border carbon adjustments. We compare the results in the sensitivity analysis to the results from Sect. 3, which we refer to as the central case.

We find that while altering these assumptions affect the magnitude of policy impacts, our qualitative findings regarding the effectiveness of carbon tariffs in reducing leakage,

\footnotetext{
${ }^{28}$ In special cases, this effect can have detrimental consequences for individual domestic industries which ought to be protected via carbon tariffs (Böhringer et al. 2015).
} 
improving global cost-savings and its potential to shift the economic burden of emission reduction from regulating to non-regulating regions remain robust.

For brevity and compactness, our results representation focuses on carbon leakage and burden-shifting - we skip reporting on the global cost, which remains very similar to the core setting results throughout the sensitivity analysis.

\section{Appendix 2.1: Trade Elasticities and Fossil Fuel Supply Elasticities}

We test the sensitivity of our results to the degree of price-responsiveness of trade flows and fossil fuel supply, which are key drivers of the leakage rate and the cost incidence of unilateral emission pricing. We consider the cases where we either halve or double the Armington elasticities (denoted REF_arm-lo, TRF_arm-lo, REF_arm-hi, and TRF_armhi) or the fossil fuel supply elasticities (denoted REF_ffs-lo, TRF_ffs-lo, REF_ffs-hi, and TRF_ffs-hi, respectively) compared to our core setting.

As illustrated in Fig. 17, lowering the Armington elasticities under both REF and TRF scenarios reduces the leakage rate. This effect is due to the lower substitutability between domestic and foreign goods, dis-incentivizing shifts in production from OECD, and redirection of trade flows by Non-OECD countries. On the other hand, doubling the Armington elasticities increases relocation and emission leakage. The effectiveness of the tariff in terms of leakage reduction under both high and low Armington elasticities are consistent with the trend we observed in the core results in Fig. 8. Again, we observe three distinct phases: an increasing emission reduction effect of tariffs from 2001 to 2006 and a steep decline during the financial crisis (2007-2008). The effectiveness of tariffs in reducing leakage picks-up again post the financial crises (2010-2011) but remains largely stable between 2011 and 2014. This trend correlates strongly with the pattern of the relative importance of OECD embodied emissions import from Non-OECD.

In terms of the abatement burden, halving the Armington elasticities increases the share of the economic burden on Non-OECD countries under unilateral emission pricing standalone (REF_arm-lo) and the tendency of the carbon-based tariffs to shift the abatement burden (TRF_arm-lo), see Fig. 18. With reduced trade-responsiveness to price changes, the ability to pass through cost increases for OECD countries such that from 2005 onward, Non-OECD bear almost all the cost of emission abatement in OECD. In contrast, increasing trade responsiveness leads to a pronounced increase in the share of the cost of the policy borne by OECD under emission pricing stand-alone (REF_arm-hi) such that between 2009 and 2014, OECD bears a larger share of the global cost incidence. The burden-shifting potential of tariffs declines towards higher Armington elasticities because of stronger trade diversion by Non-OECD countries away from the OECD to other Non-OECD countries (TRF_arm-hi). Nevertheless, the burden-shifting potential of carbon tariffs (see Fig. 19) remains substantial and even increases for some periods (e.g., 2002-2008 and 2009-2012), and a significant share of the cost falls on Non-OECD countries throughout the period. The results in Figs. 18 and 19 thus show that OECD welfare improves when unilateral emission pricing is complemented with tariffs at the border.

For fossil fuel supply elasticities, the results in Fig. 20 show that halving the fossil fuel supply elasticities leads to a higher leakage rate-as compared to the benchmark leakage rate in Fig. 8 while doubling the fossil fuel supply elasticities reduces benchmark leakage rate under emission pricing stand-alone. That is, a reduced sensitivity of fuel supply to the fall in the OECD fossil fuel demand triggers a more pronounced depression of international fuel prices and hence higher consumption of fossil fuels in Non-OECD countries. 


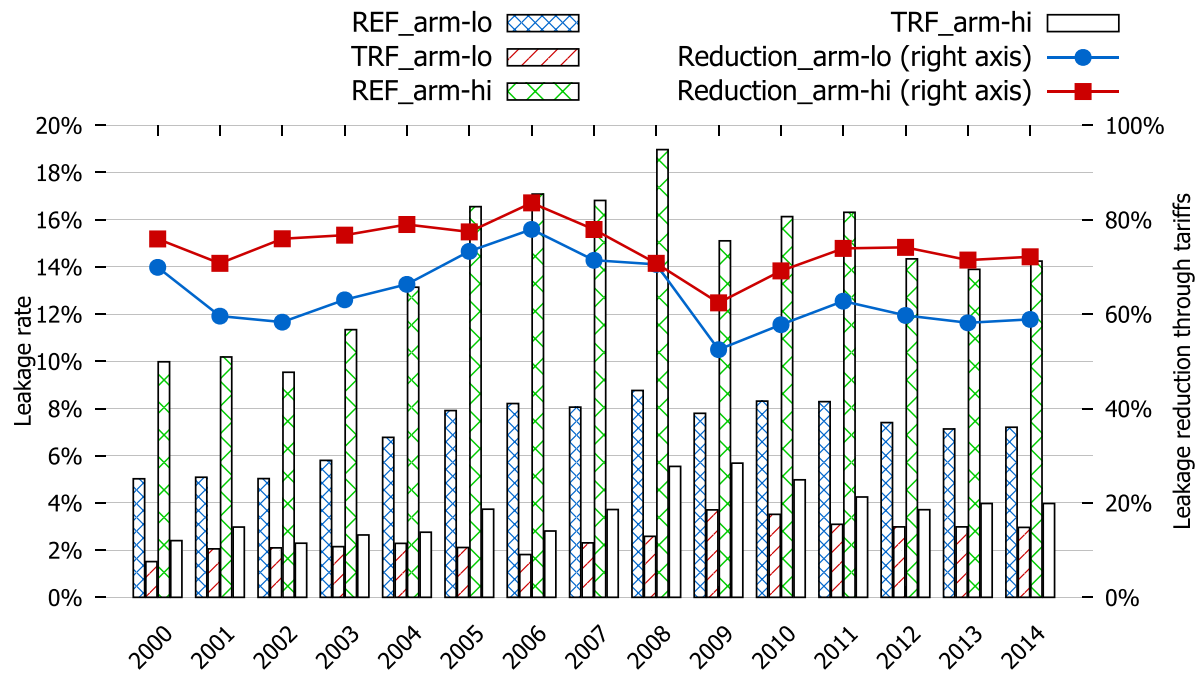

Fig. 17 Leakage rates under halved (REF_arm-lo and TRF_arm-lo) and doubled (REF_arm-hi and TRF_ arm-hi) Armington elasticities

Thus, with low supply elasticities, tariffs' efficacy to reduce leakage does not increase over time. However, under TRF, doubling the supply elasticities shuts down both the competitive and fossil-fuel price channels of emission leakage to the extent that emission reduction even occurs in Non-OECD countries across all the years. Across alternative choices of fossil fuel supply elasticities, however, the potential to shift the abatement burden to nonabating countries and therefore relative welfare improvement in OECD (see, Figs. 21 and 22) remains qualitatively identical to the core simulations.

\section{Appendix 2.2: Fixed $\mathrm{CO}_{2}$ Price, Reduction Target, Coalition Size, and Carbon-Based Rebates to Exports}

Figures 23 and 24 show the results on carbon leakage and burden-shifting if we introduce a fixed $\mathrm{CO}_{2}$ emission price within the range of 5-30 USD under unilateral emission pricing stand-alone (REF) and the tariff scenario (TRF). ${ }^{29}$ We observe a very similar leakage effect as in our central case simulation and the effectiveness of tariffs in terms of reducing leakage follows the same trend (see, Fig. 8). However, for each year, the leakage reduction effect of tariff increases marginally with higher $\mathrm{CO}_{2}$ emission price.

As to burden-shifting (Fig. 24), we find that OECD countries are even better off under both REF and TRF for lower $\mathrm{CO}_{2}$ prices (5-10 USD) than in the business-asusual for the years 2000-2014. ${ }^{30}$ For higher $\mathrm{CO}_{2}$ prices (15-30 USD), on the other hand, OECD countries are better off under TRF for the period 2004-2014. This effect is due to the increasing ability to pass through cost (recall Fig. 2) while holding the $\mathrm{CO}_{2}$

\footnotetext{
29 The $\mathrm{CO}_{2}$ taxes are in real 2007 USD. Since WIOD reports data in current USD, we deflate the $\mathrm{CO}_{2}$ tax with the implicit price deflators for GDP from the Bureau of Economic Analysis (BEA 2016).

${ }^{30}$ For brevity and compactness, we only report the economic adjustment cost results for only the years 2000, 2007, and 2014. The results for all other years, however, remain similar to the ones reported.
} 


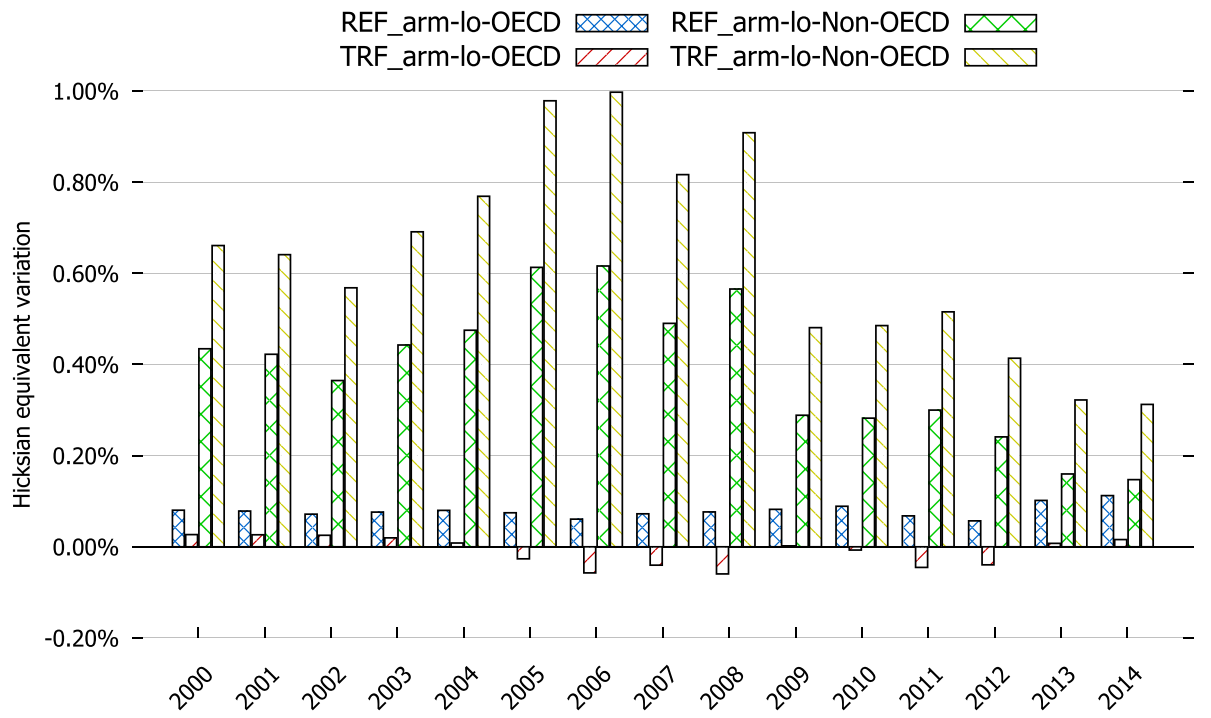

Fig. 18 Economic adjustment cost in OECD and Non-OECD under halved Armington elasticities. Note Costs are reported as Hicksian equivalent variation as a percentage share of business-as-usual income
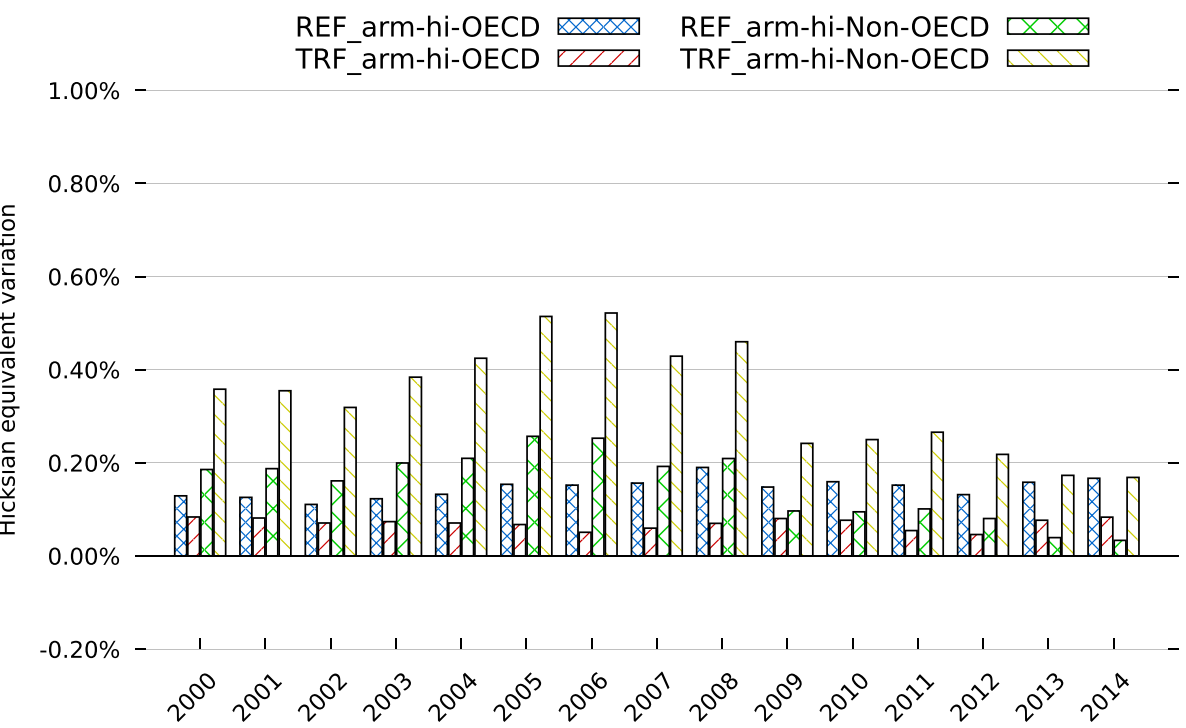

Fig. 19 Economic adjustment cost in OECD and Non-OECD under doubled Armington elasticities. Note Costs are reported as Hicksian equivalent variation as a percentage share of business-as-usual income

emission price constant. While a large part of the emission reduction cost is shifted to Non-OECD countries under emission pricing alone, the introduction of tariffs further improves OECD welfare with increasing $\mathrm{CO}_{2}$ price at the expense of Non-OECD. The burden-shifting through tariffs is, however, slightly less pronounced in the later years 


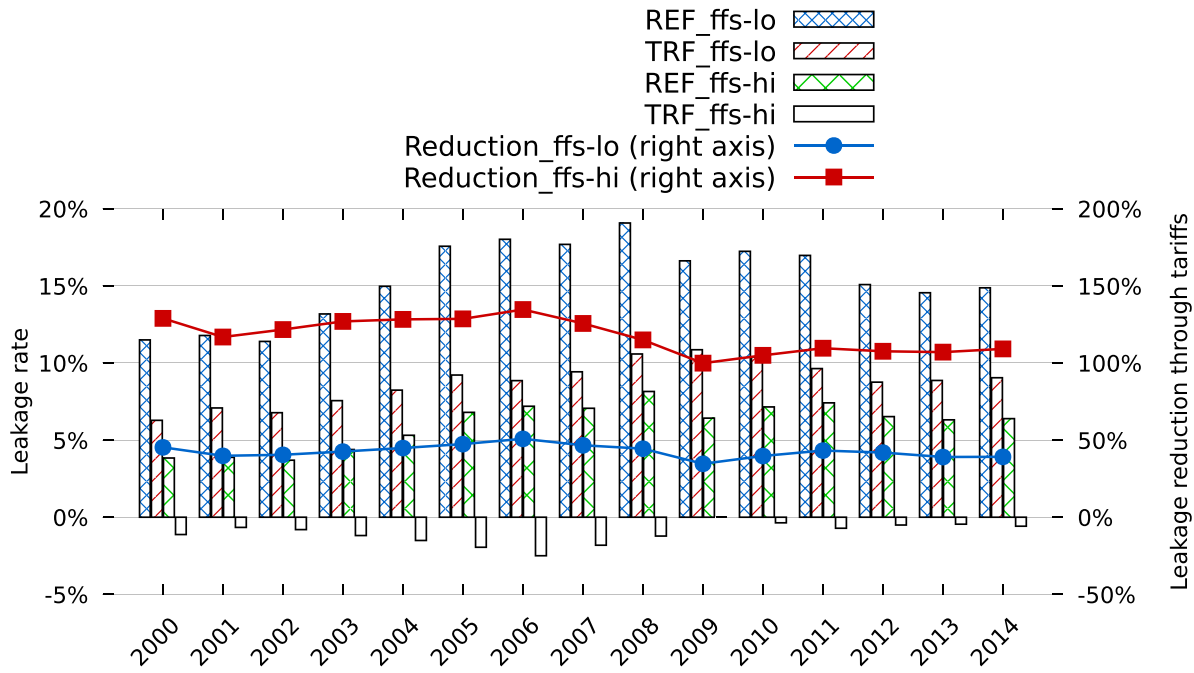

Fig. 20 Leakage rates under halved (REF_ffs-lo and TRF_ffs-lo) and doubled (REF_ffs-hi and TRF_ffs-hi) fossil fuel supply elasticities

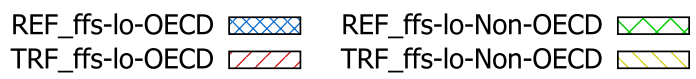

$1.00 \%-$
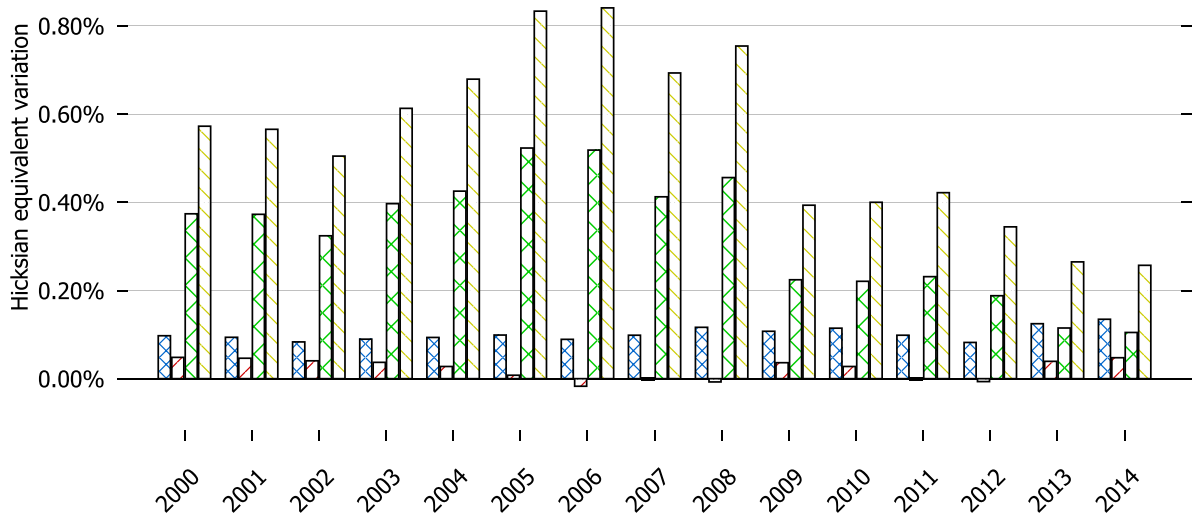

Fig. 21 Economic adjustment cost in OECD and Non-OECD under halved fossil fuel supply elasticities. Note Costs are reported as Hicksian equivalent variation as a percentage share of business-as-usual income

due to the lower $\mathrm{CO}_{2}$ emission prices as compared to the central case scenarios (see Fig. 12).

To test how the stringency of unilateral climate policy affects our main findings, we consider alternative emission reduction targets within the range of 5-30\%. Again, Fig. 25 exhibits a similar trend as in the central case simulations (reduction target 20\%) regarding the effectiveness of carbon tariffs to reduce leakage. The main difference 


$$
\begin{array}{ll}
\text { REF_ffs-hi-OECD } \square \times \square & \text { REF_ffs-hi-Non-OECD } \square \times \square \\
\text { TRF_ffs-hi-OECD } & \text { TRF_ffs-hi-Non-OECD } \square
\end{array}
$$

$1.00 \%$
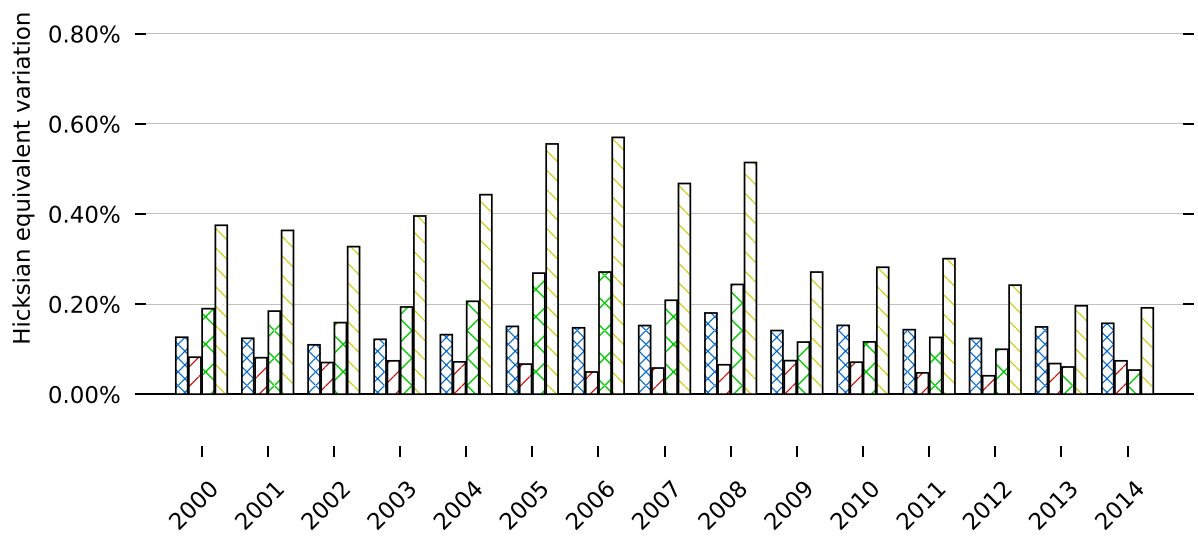

Fig. 22 Economic adjustment cost in OECD and Non-OECD under doubled fossil fuel supply elasticities. Note Costs are reported as Hicksian equivalent variation as a percentage share of business-as-usual income
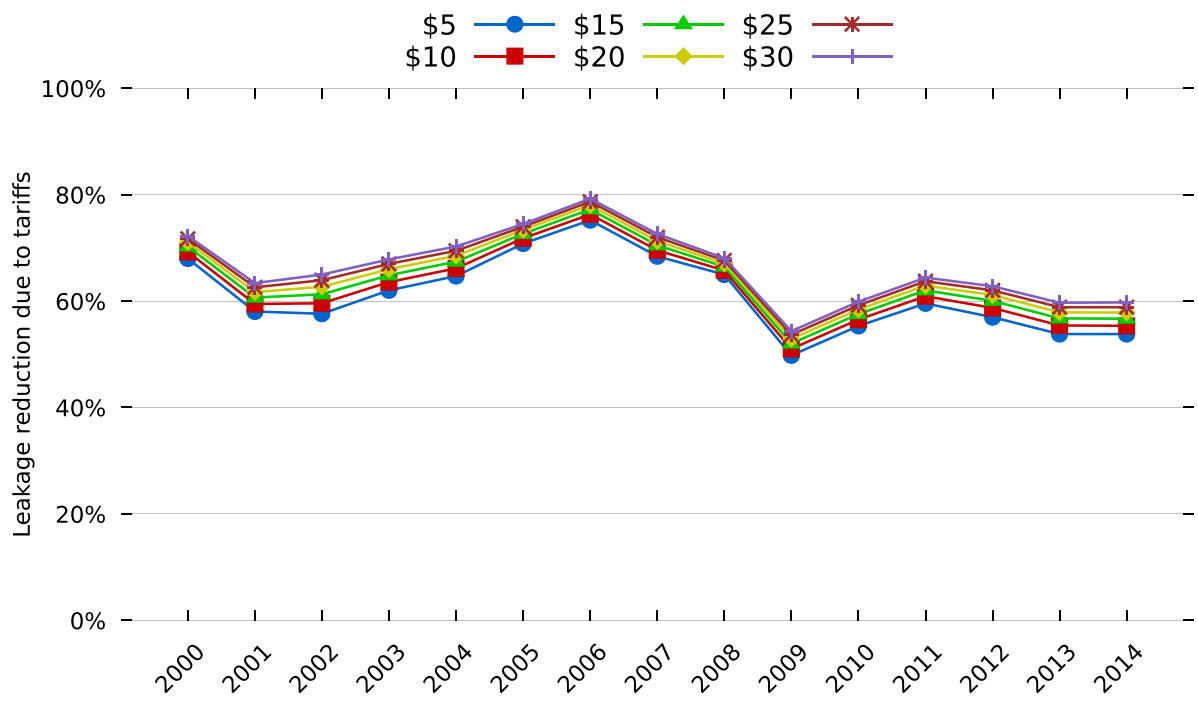

Fig. 23 Leakage reduction due to tariffs for different $\mathrm{CO}_{2}$ prices

when moving from lower to more stringent reduction targets is the cost distribution between OECD and Non-OECD under REF, depicted in Fig. 26. For 5-10\% reduction targets, Non-OECD countries almost entirely bear the cost of abatement, and across several years OECD countries even face negative cost under REF. For lower reduction targets, which entail lower $\mathrm{CO}_{2}$ prices, OECD countries can almost entirely pass through increased production cost to Non-OECD trading partners. As $\mathrm{CO}_{2}$ emission prices 


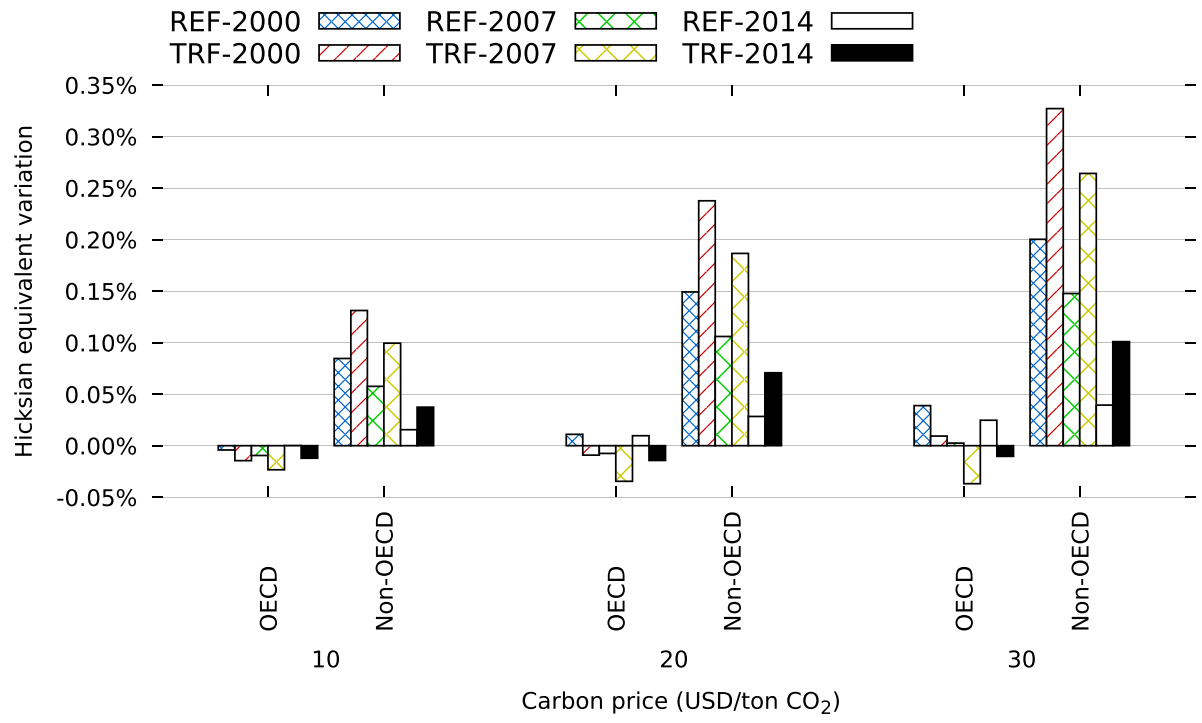

Fig. 24 Economic adjustment cost in OECD and Non-OECD countries under REF and TRF with different $\mathrm{CO}_{2}$ prices. Note Costs are reported as Hicksian equivalent variation as a percentage share of business-asusual income
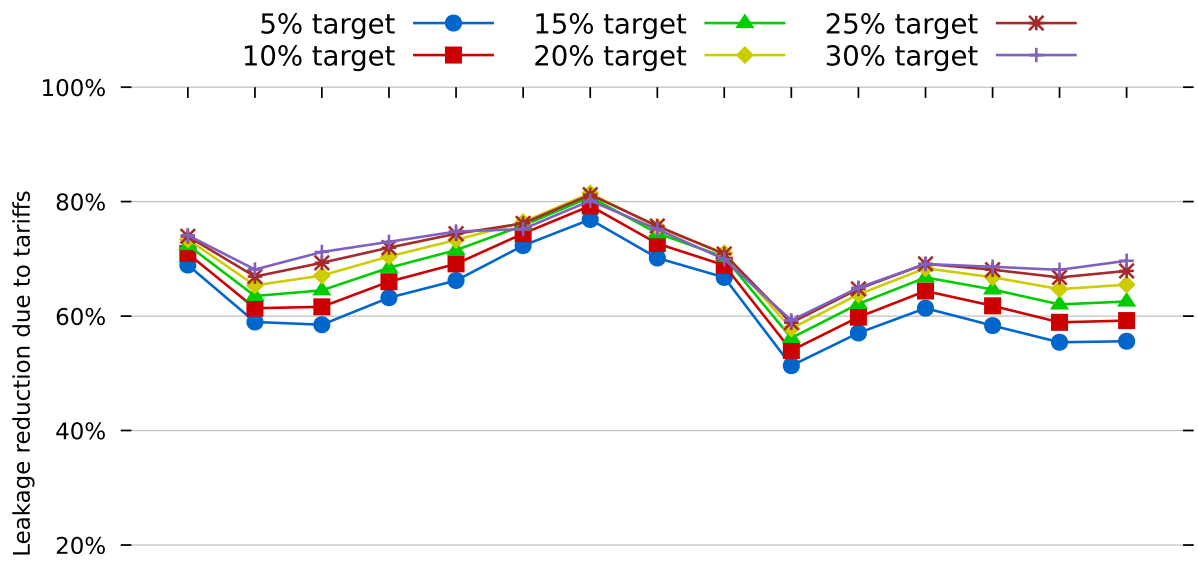

$0 \%$

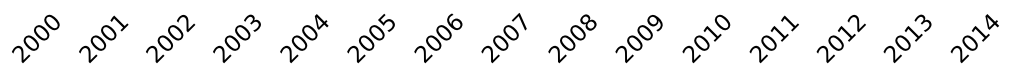

Fig. 25 Leakage reduction due to tariffs for 5-30\% reduction targets

increase to achieve higher emission reduction targets (25-30\%), the terms of trade changes are no longer sufficient to offset the increasing cost of emission abatementOECD countries are then left with a substantial share of the overall policy burden. Note, however, that our key insight on the burden-shifting potential of tariffs remains robust 


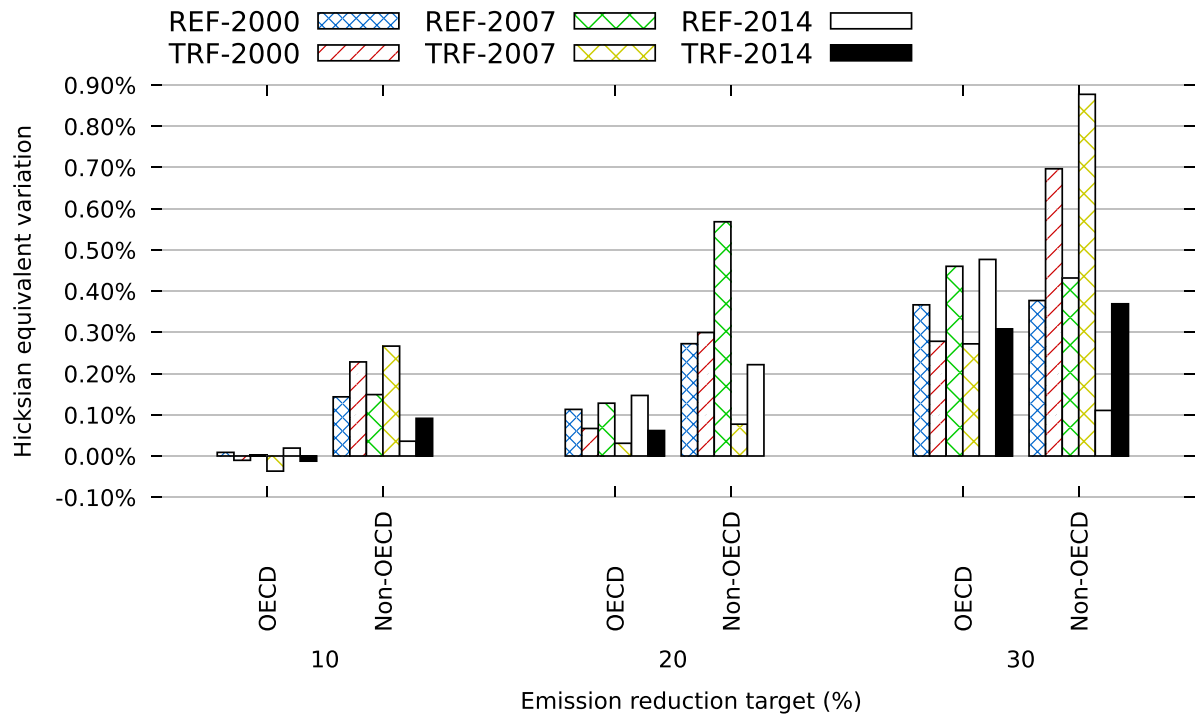

Fig. 26 Economic adjustment cost in OECD and Non-OECD countries under different emission reduction targets. Note Costs are reported as Hicksian equivalent variation as a percentage share of business-as-usual income

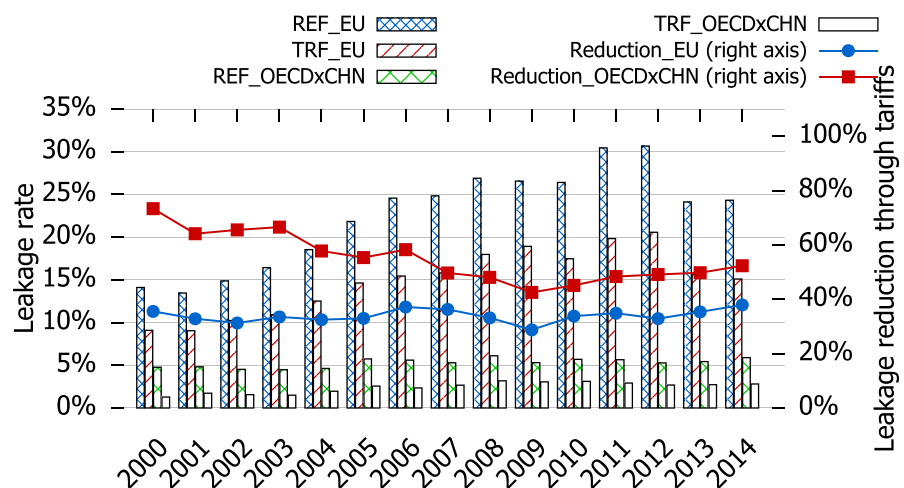

Fig. 27 Leakage rates under EU action (REF_EU and TRF_EU) as well as joint action by OECD and China (REF_OECDxCHN and TRF_OECDxCHN)

across different levels of stringency in emission abatement. Over time, the potency of carbon tariffs to shift the burden of abatement from OECD to Non-OECD countries persists across all reduction targets. This further makes OECD better off in terms of relative welfare gains as compared to Non-OECD countries over the period.

Concerning regional coverage of the unilateral climate policy, we test the sensitivity of our main findings by considering the European Union (EU) as a smaller coalition and OECD plus China as a larger abating coalition while maintaining the reduction target of $20 \%$ of the respective regions' benchmark emissions. The policy scenarios are 


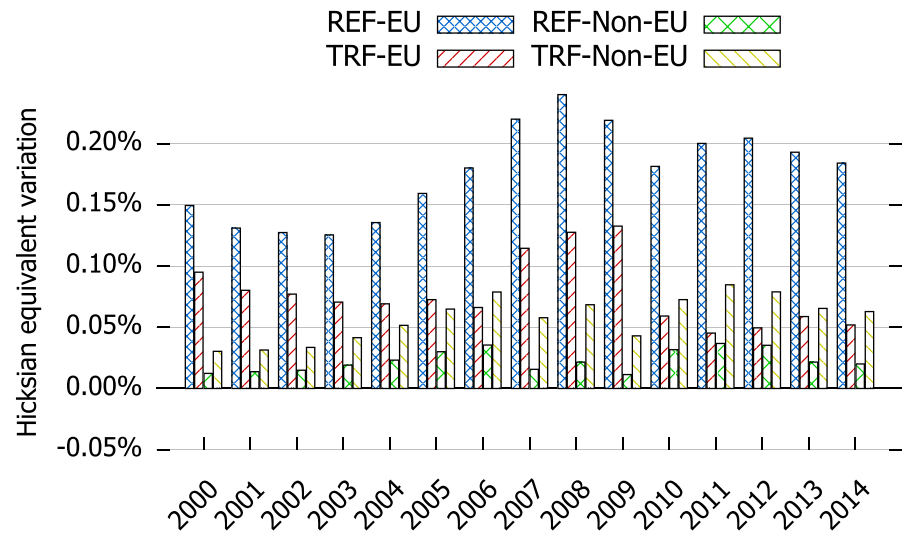

Fig. 28 Economic adjustment cost with EU as climate coalition. Note Costs are reported as Hicksian equivalent variation as a percentage share of business-as-usual income
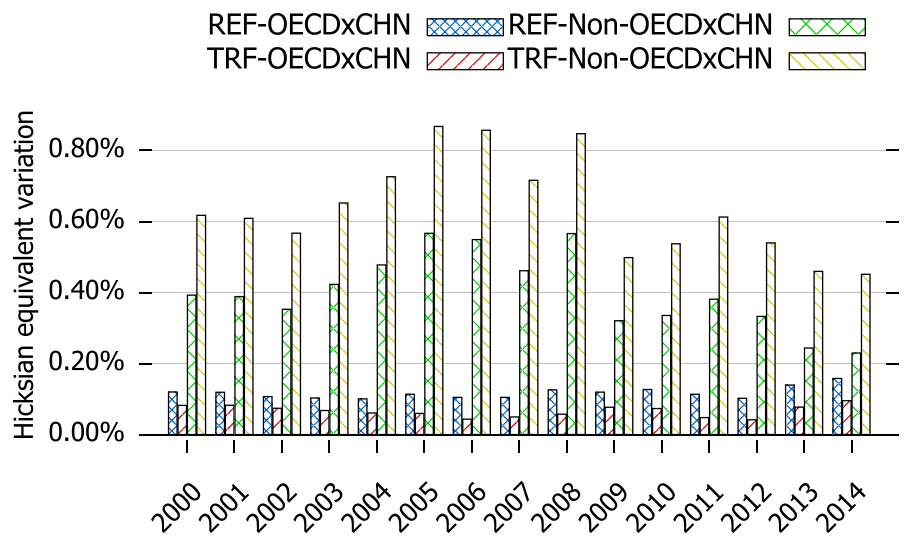

Fig. 29 Economic adjustment cost with OECD plus China as climate coalition. Note Costs are reported as Hicksian equivalent variation as a percentage share of business-as-usual income

denoted REF_EU and TRF_EU for EU action, as well as REF_OECDxCHN and TRF_ OECDxCHN for joint action of OECD countries and China, respectively. Figure 27 shows the leakage rate for emission pricing stand-alone (REF_EU and REF_OECDxCHN) and emission pricing complemented with carbon tariffs (TRF_EU and TRF_OECDxCHN). As expected, the leakage rate decreases as coalition size increases. The leakage rate for EU action under the reference scenario ranges from 14 to $31 \%$, while emission pricing in OECD plus China causes leakage rates between 4 and $6 \%$ over the period. We also find that the average tariffs reduction effect is $35 \%$ for the EU and $55 \%$ for the OECD plus China coalition. In line with the core scenarios, the potential of carbon tariffs to attenuate leakage does not consistently trend up over the period.

Figures 28 and 29 depict the burden-shifting towards non-abating regions. Here, we find that the coalition size affects the cost incidence. As shown in Fig. 28, the EU bears a larger share of the global cost than Non-EU throughout the period. This is not surprising since the EU ETS - which is reflected in the benchmark data- has led to a sharp decline in $\mathrm{CO}_{2}$ 


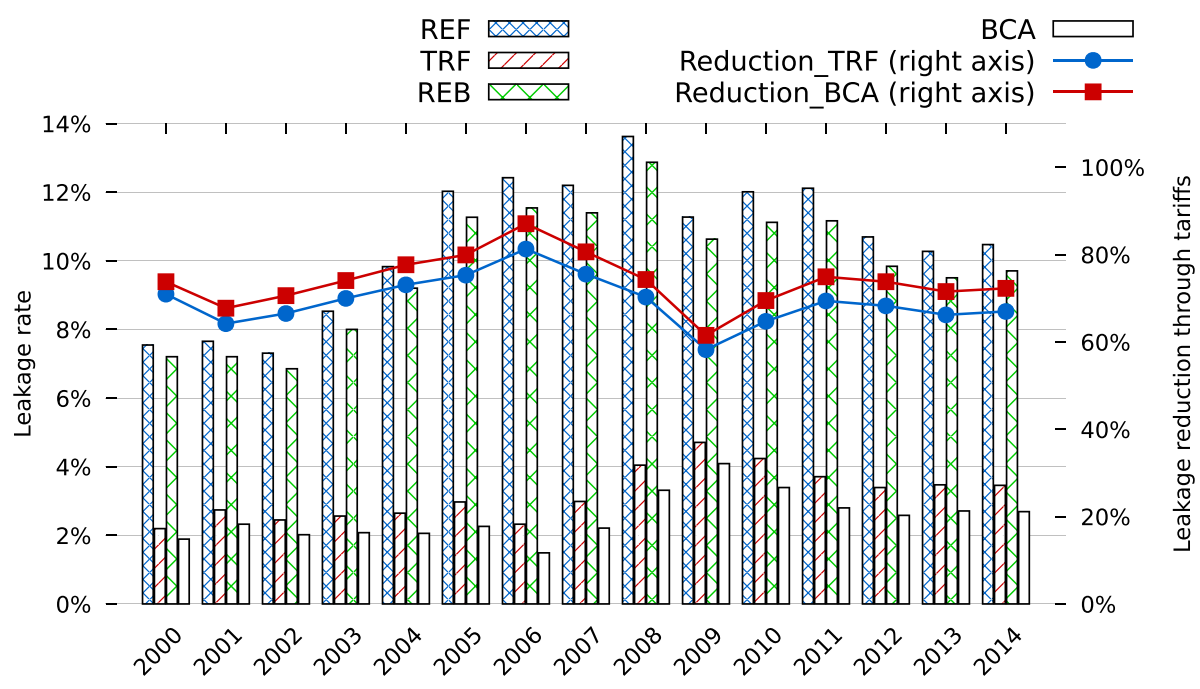

Fig. 30 Leakage rates under REF, TRF, REB, and BCA

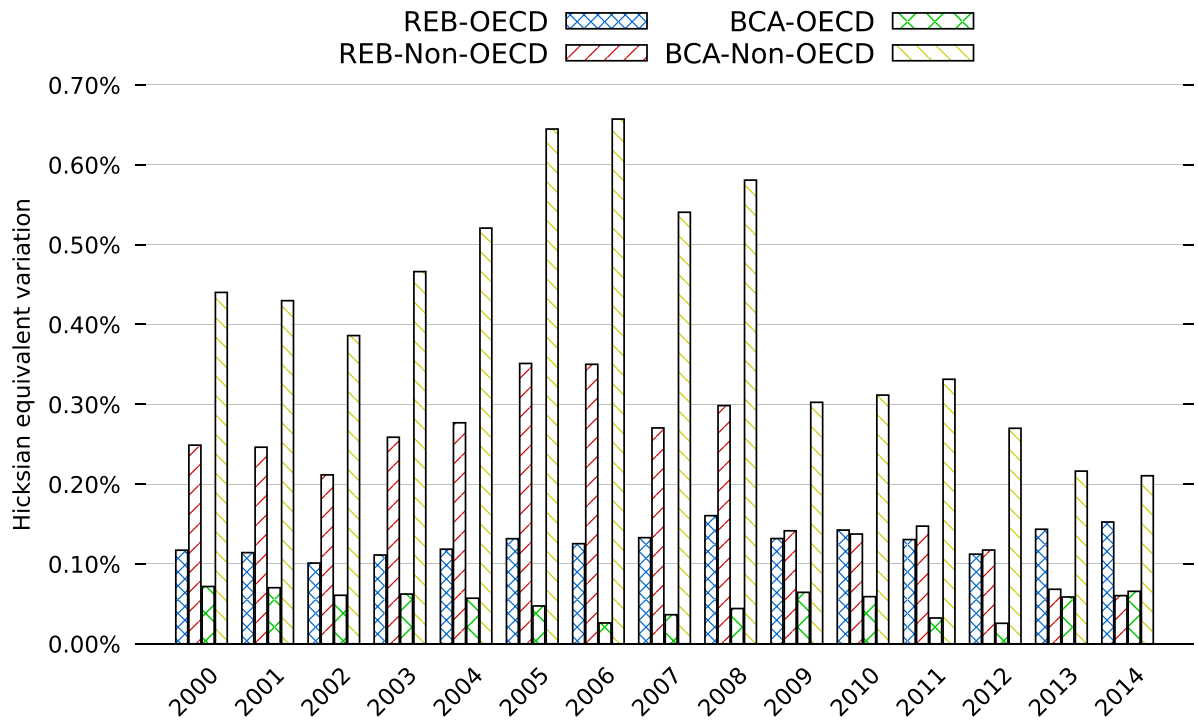

Fig. 31 Economic adjustment cost in OECD and Non-OECD countries under REB and BCA. Note Costs are reported as Hicksian equivalent variation as a percentage share of business-as-usual income

intensity of EITE production compared to other regions. Consequently, the EU requires higher domestic $\mathrm{CO}_{2}$ prices to achieve the $20 \%$ reduction target but may be less capable of shifting a larger share of the cost to Non-EU countries. In the larger coalition (OECD plus China, Fig. 29), the burden-shifting potential of carbon-based tariffs increases because the OECD plus China is better able to pass-through the abatement cost. Except for the EU ETS effect, our key insights that carbon tariffs significantly reduce leakage and shift the 
Table 2 Denotations used in the MRIO calculations

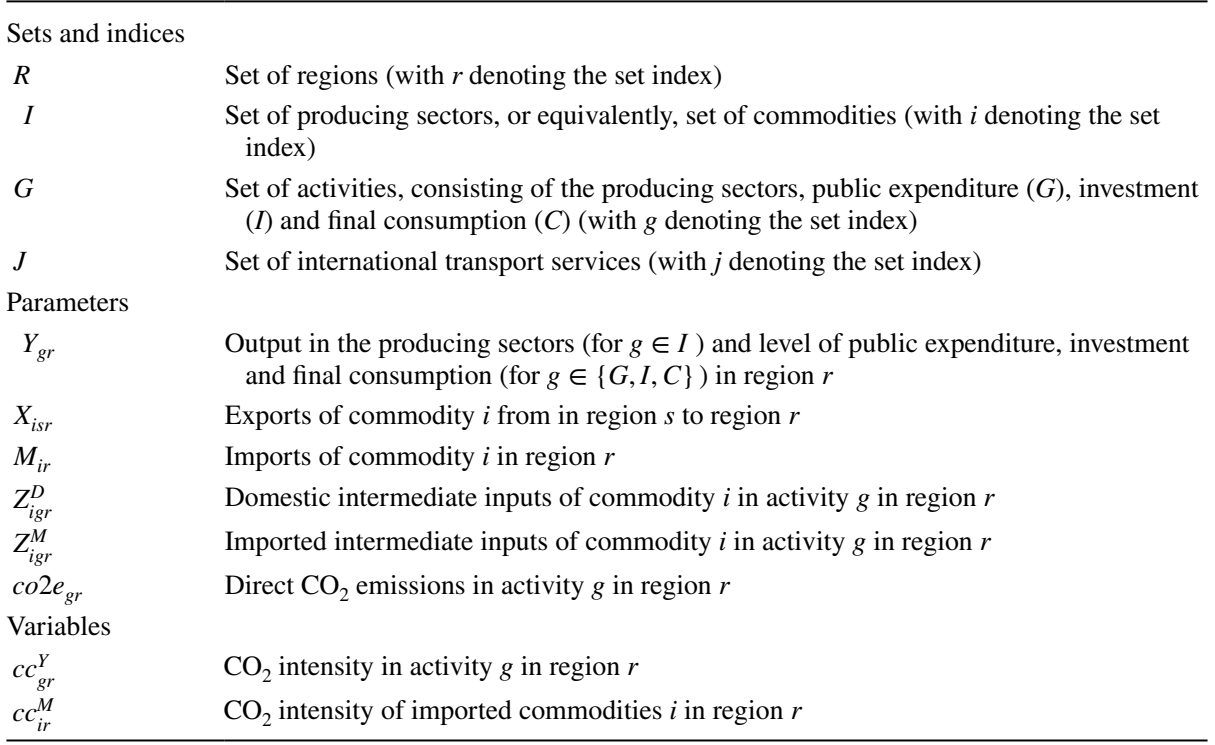

abatement burden to non-abating regions remain robust even when the abating coalition's regional coverage is expanded.

To account for alternative designs of border carbon adjustments, we introduce two additional scenarios. In the variant REB, we use carbon-based rebates on the direct $\mathrm{CO}_{2}$ intensity of EITE exports as a supplementary instrument to uniform $\mathrm{CO}_{2}$ emission pricing. In the scenario BCA, we include both carbon-based import tariffs and export rebates in addition to $\mathrm{CO}_{2}$ pricing - that is, the variant $\mathrm{BCA}$ considers a comprehensive border carbon adjustment scheme. We show leakage results in Fig. 30 and regional cost implications in Fig. 31. The REB variant results are very similar to REF, while BCA results are similar to TRF. The reason is that only $8 \%$ of output for EITE industries in OECD countries are exported to Non-OECD countries. Thus, direct carbon emissions embodied in exports to Non-OECD countries play only a minor role for OECD countries.

\section{Appendix 3: Multi-region Input-Output Model}

For our MRIO calculation of carbon embodied in trade flows and final products, we use the denotations listed in Table 2. The calculation is identical for each year in our analysis (2000-2014), so we omit an index to indicate the year.

The total $\mathrm{CO}_{2}$ intensity of a good is composed of the $\mathrm{CO}_{2}$ emitted in the production of the good itself as well as of the $\mathrm{CO}_{2}$ that is emitted to produce intermediate inputs and international transport services. To calculate the full $\mathrm{CO}_{2}$ intensity (per US\$ of output), we use input-output accounting identities and solve the associated linear system of equations below for the carbon intensity of production activities $c c_{g r}^{Y}$ and the carbon intensity of imports $c c_{i r}^{M}$. The first set of Eq. (1) states that the total embodied emissions in output $c c_{g r}^{Y} Y_{g r}$ of activity $g$ in region $r$ must be equal to the sum of direct emissions, the embodied emissions in domestic intermediate inputs, and the embodied emissions in 
imported intermediate inputs. The second set of Eq. (2) demands total embodied emission in imports $c c_{i r}^{M} M_{i r}$ of commodity $i$ in region $r$ to equal the sum of the embodied emission of all exports from regions $s$ to $r$.

$$
\begin{gathered}
\forall g \forall r \quad c c_{g r}^{Y} Y_{g r}=c o 2 e_{g r}+\sum_{i} c c_{i r}^{M} Z_{i g r}^{M}+\sum_{i} c c_{g r}^{Y} Z_{i g r}^{D} \\
\forall i \forall r \quad c c_{i r}^{M} M_{i r}=\sum_{s} c c_{i s}^{Y} X_{i s r}
\end{gathered}
$$

We obtain a system of $(\operatorname{Card}(G)+\operatorname{Card}(I)) \times \operatorname{Card}(R)$ unknowns and linear equations. The MRIO model can be solved directly as a square system of equations or solved recursively using a diagonalization algorithm. The data for the parameters are provided by the WIOD.

\section{Appendix 4: Computable General Equilibrium Model}

The computable general equilibrium (CGE) model builds on the model developed to assess border carbon adjustments in Böhringer et al. (2018). The model is formulated as a mixed complementarity problem (Rutherford 1995), and solved with the PATH solver (Dirkse and Ferris 1995; Ferris and Munson 2000) in GAMS. The competitive equilibrium is characterized by three classes of conditions: zero profit conditions for all economic activities, market clearance for all markets, and income balance for all agents. We use the notation $\Pi_{i r}^{u}$ to denote the profit function of sector $i$ in region $r$ where $u$ denotes the associated production activity. We apply Hotelling's lemma to represent compensated demand and supply functions, and we express the constant-elasticity-ofsubstitution cost functions in calibrated share form (see e.g. Böhringer et al. 2003). Indices $i$ and $j$ index commodities, including a composite public good $G$ and a composite investment good $I$. Indices $r$ and $s$ index regions. The label $E G$ represents the set of energy goods, and the label $F F$ denotes the subset of fossil fuels. The notations used are summarized in Tables 3, 4, 5, 6, 7 and 8 .

\section{Appendix 4.1: Zero Profit Conditions}

1. Production of goods except fossil fuels $(i \notin F F)$

$$
\begin{aligned}
\Pi_{i r}^{Y}= & p_{i r}-\left\{\left(\sum_{j \notin E G} \theta_{j i r} p_{j r}^{A}\right)^{1-\sigma_{i r}^{K L E M}}-\theta_{i r}^{K L E}\left[\theta_{i r}^{K L E} p_{E, i r}^{1-\sigma_{i r}^{K L E}}\right.\right. \\
& \left.\left.+\left(1-\theta_{i r}^{E}\right)\left(\theta_{i r}^{L} w_{r}^{1-\sigma_{i r}^{K L}}+\left(1-\theta_{i r}^{L}\right) v_{r}^{1-\sigma_{i r}^{K L}}\right)^{\frac{1-\sigma_{i r}^{K L E}}{1-\sigma_{i r}^{K L}}}\right]^{\frac{1-\sigma_{i r}^{K L E M}}{1-\sigma_{i r}^{K L E}}}\right\}^{\frac{1}{1-\sigma_{i r}^{K L M}}} \leq 0
\end{aligned}
$$

2. Production of fossil fuels $(i \in F F)$ 
Table 3 Sets and indexes

\begin{tabular}{ll}
\hline$i, j$ & Indexes for sectors and goods \\
$r, s$ & Indexes for regions \\
$E G$ & $\begin{array}{l}\text { All energy goods: coal, crude oil, natural gas (aggregated in sector mining and quarrying), } \\
\text { refined oil, and electricity }\end{array}$ \\
FF & Primary fossil fuels: coal, crude oil, natural gas (aggregated in sector mining and quarrying) \\
\hline
\end{tabular}

Table 4 Activity variables

\begin{tabular}{ll}
\hline$Y_{i r}$ & Production in sector $i$ and region $r$ \\
$E_{i r}$ & Aggregate energy input in sector $i$ and region $r$ \\
$M_{i r}$ & Aggregate imports of good $i$ and region $r$ \\
$A_{i r}$ & Armington aggregate for good $i$ in region $r$ \\
$C_{r}$ & Aggregate household consumption in region $r$ \\
\hline
\end{tabular}

Table 5 Price variables

\begin{tabular}{ll}
\hline$p_{i r}$ & Output price of good $i$ produced in region $r$ \\
$p_{i r}^{E}$ & Price of aggregate energy in sector $i$ and region $r$ \\
$p_{i r}^{M}$ & Import price aggregate for good $i$ imported to region $r$ \\
$p_{i r}^{A}$ & Price of Armington good $i$ in region $r$ \\
$p_{r}^{C}$ & Price of aggregate household consumption in region $r$ \\
$w_{r}$ & Wage rate in region $r$ \\
$v_{r}$ & Price of capital services in region $r$ \\
$q_{i r}$ & Rent to natural resources in region $r(i \in F F)$ \\
$p_{r}^{\mathrm{CO}_{2}}$ & $\mathrm{CO}_{2}$ emission price in region $r$ \\
\hline
\end{tabular}

Table 6 Cost shares

\begin{tabular}{ll}
\hline$\theta_{j i r}$ & Cost share of intermediate good $j$ in sector $i$ and region $r$ \\
$\theta_{i r}^{K L E}$ & Cost share of value-added and energy in sector $i$ and region $r$ \\
$\theta_{i r}^{E}$ & Cost share of energy composite in the $K L E$ aggregate in sector $i$ and region $r(i \notin F F)$ \\
$\theta_{i r}^{L}$ & Cost share of labor in value-added composite of sector $i$ and region $r$ \\
$\theta_{i r}^{Q}$ & Cost share of natural resources in sector $i$ and region $r(i \in F F)$ \\
$\theta_{T i r}^{F F}$ & Cost share of good $i(T=i)$ or labor $(T=L)$ or capital $(T=K)$ in sector $i$ and region $r(i \in F F)$ \\
$\theta_{j i r}^{E G}$ & Cost share of energy good $j$ in the energy composite in sector $i$ in region $r(i \notin F F)$ \\
$\theta_{i s r}^{M}$ & Cost share of imports of good $i$ from region $s$ to region $r$ \\
$\theta_{i r}^{A}$ & Cost share of domestic variety in Armington good $i$ of region $r$ \\
$\theta_{C r}^{E}$ & Cost share of energy composite in household consumption region $r(i \notin F F)$ \\
$\gamma_{i r}$ & Cost share of non-energy good i in non-energy household consumption demand in region $r$ \\
\hline
\end{tabular}


Table 7 Elasticities

$\sigma_{i r}^{K L E M}$ Substitution between KLE composite and material inputs in pro- $\quad$ Koesler and Schymura (2015) duction

$\sigma_{i r}^{K L E} \quad$ Substitution between energy and value-added in production

Koesler and Schymura (2015)

$\sigma_{i r}^{K L} \quad$ Substitution between labor and capital in value-added composite

Koesler and Schymura (2015)

$\sigma_{i r}^{Q} \quad$ Substitution between natural resources and otherinputs in fossil fuel $\mu_{O M N}=1.0$ production calibrated to exogenous supply elasticities

$\sigma_{i r}^{E G} \quad$ Substitution between energy goods in the energy aggregate

0.5

$\sigma_{i r}^{A} \quad$ Substitution between the import aggregate and the domestic input

Aguiar et al. (2016)

$\sigma_{i r}^{M} \quad$ Substitution between imports from different regions

Aguiar et al. (2016)

$\sigma_{C r}^{E} \quad$ Substitution between energy and material inputs in consumption

0.3

$$
\begin{aligned}
\Pi_{i r}^{Y}= & p_{i r}-\left[\theta_{i r}^{Q} q_{i r}^{1-\sigma_{i}^{Q}}+\left(1-\theta_{i r}^{Q}\right)\left(\theta_{L i r}^{F F} w_{r}+\theta_{K i r}^{F F} v_{r}\right.\right. \\
& \left.\left.+\sum_{j} \theta_{j i r}^{F F}\left(p_{i r}^{A}+p_{r}^{C O_{2}} a_{j}^{C O_{2}}\right)\right)^{1-\sigma_{i}^{Q}}\right]^{\frac{1}{1-\sigma_{i}^{Q}}} \leq 0
\end{aligned}
$$

3. Sector-specific energy aggregate $(i \notin F F)$

$$
\Pi_{i r}^{E}=p_{i r}^{E}-\left(\sum_{j \in E G} \theta_{j i r}^{E G}\left(p_{j r}^{A}+p_{r}^{C O^{2}} a_{j}^{C O^{2}}\right)^{1-\sigma_{i r}^{E G}}\right)^{\frac{1}{1-\sigma_{i r}^{E G}}} \leq 0
$$

\section{Armington aggregate $(i \notin F F)$}

$$
\Pi_{i r}^{A}=p_{i r}^{A}-\left(\theta_{i r}^{A} p_{i r}^{1-\sigma_{i r}^{A}}+\left(1-\theta_{i r}^{A}\right) p_{M, i r}^{1-\sigma_{i r}^{A}}\right)^{\frac{1}{1-\sigma_{i r}^{A}}} \leq 0
$$

5. Aggregate imports across regions

$$
\Pi_{i r}^{M}=p_{i r}^{M}-\left(\sum_{s} \theta_{i s r}^{M} p_{i s}^{1-\sigma_{i r}^{M}}\right)^{\frac{1}{1-\sigma_{i r}^{M}}} \leq 0
$$

\section{Household consumption demand}

Table 8 Endowments and emissions coefficients

\begin{tabular}{ll}
\hline $\bar{L}_{r}$ & Aggregate labor endowment in region $r$ \\
$\bar{K}_{r}$ & Aggregate capital endowment in region $r$ \\
$\bar{Q}_{i r}$ & Endowment of natural resource $i$ in region $r$ \\
$\bar{G}_{r}$ & Public good provision in region $r$ \\
$\bar{I}_{r}$ & Investment demand in region $r$ \\
$\bar{B}_{r}$ & Balance of payment deficit or surplus in region $r$ \\
$\overline{\mathrm{CO}}_{r}$ & $\mathrm{CO}_{2}$ emission constraint for region $r$ \\
$a_{i}^{\mathrm{CO}}$ & $\mathrm{CO}_{2}$ emissions coefficient for fossil fuel $i$ \\
\hline
\end{tabular}




$$
\Pi_{r}^{C}=p_{r}^{C}-\left(\theta_{C r}^{E} p_{E, C r}^{1-\sigma_{C r}^{E}}+\left(1-\theta_{C r}^{E}\right)\left[\prod_{i \notin E G} p_{A, i r}^{\gamma_{i r}}\right]^{1-\sigma_{C r}^{E}}\right)^{\frac{1}{1-\sigma_{C r}^{E}}} \leq 0
$$

\section{Market Clearance Conditions}

7. Labor

$$
\bar{L}_{r} \geq \sum_{i} Y_{i r} \frac{\partial \Pi_{i r}^{Y}}{\partial w_{r}}
$$

8. Capital

$$
\bar{K}_{r} \geq \sum_{i} Y_{i r} \frac{\partial \Pi_{i r}^{Y}}{\partial v_{r}}
$$

9. Natural resources $(i \in F F)$

$$
\bar{Q}_{i r} \geq Y_{i r} \frac{\partial \Pi_{i r}^{Y}}{\partial q_{i r}}
$$

10. Output

$$
Y_{i r} \geq \sum_{j} A_{j r} \frac{\Pi_{j r}^{A}}{\partial p_{i r}}+\sum_{s} M_{i s} \frac{\partial \Pi_{i s}^{M}}{\partial p_{i r}}
$$

11. Armington aggregate

$$
A_{i r} \geq \sum_{j} Y_{j r} \frac{\Pi_{j r}^{Y}}{\partial p_{i r}}+C_{r} \frac{\partial \Pi_{r}^{C}}{\partial p_{i r}^{A}}
$$

12. Import aggregate

$$
M_{i r} \geq A_{i r} \frac{\Pi_{i r}^{A}}{\partial p_{i r}^{M}}
$$

13. Sector-specific energy aggregate

$$
E_{i r} \geq Y_{i r} \frac{\Pi_{i r}^{Y}}{\partial p_{i r}^{E}}
$$

14. Public consumption

$$
Y_{G r} \geq \bar{G}_{r}
$$

15. Investment

$$
Y_{I r} \geq \bar{I}_{r}
$$


16. $\mathrm{CO}_{2}$ emissions

$$
\overline{\mathrm{CO}}_{r} \geq \sum_{i} A_{i r} a_{i}^{C O_{2}}
$$

17. Household consumption (income-expenditure balance)

$$
C_{r} p_{r}^{C}=w_{r} \bar{L}_{r}+v_{r} \bar{K}_{r}+\sum_{j \in F F} q_{j r} \bar{Q}_{j r}+p_{I r} Y_{I r}+p_{G r} Y_{G r}+\bar{B}_{r}+p_{r}^{C O} \overline{C O}_{r}
$$

Funding Open Access funding enabled and organized by Projekt DEAL.

Open Access This article is licensed under a Creative Commons Attribution 4.0 International License, which permits use, sharing, adaptation, distribution and reproduction in any medium or format, as long as you give appropriate credit to the original author(s) and the source, provide a link to the Creative Commons licence, and indicate if changes were made. The images or other third party material in this article are included in the article's Creative Commons licence, unless indicated otherwise in a credit line to the material. If material is not included in the article's Creative Commons licence and your intended use is not permitted by statutory regulation or exceeds the permitted use, you will need to obtain permission directly from the copyright holder. To view a copy of this licence, visit http://creativecommons.org/licenses/by/4.0/.

\section{References}

Aguiar A, Narayanan B, McDougall R (2016) An overview of the GTAP 9 data base. J Glob Econ Anal 1(1):181-208

Armington PS (1969) A theory of demand for products distinguished by place of production. Staff PapersInternational Monetary Fund. pp 159-178

Bayer P, Aklin M (2020) The European Union emissions trading system reduced $\mathrm{CO}_{2}$ emissions despite low prices. Proc Nat Acad Sci 117(16):8804-8812

BEA (2016) National Data

Böhringer C, Rutherford T (2017) Paris after trump: an inconvenient insight. SSRN Scholarly Paper ID 2988845. Social Science Research Network, Rochester

Böhringer C, Rutherford TF, Wiegard W (2003) Computable general equilibrium analysis: Opening a black box. Technical Report 03-56, ZEW - Zentrum für Europäische Wirtschaftsforschung / Center for European Economic Research

Böhringer C, Balistreri EJ, Rutherford TF (2012) The role of border carbon adjustment in unilateral climate policy: overview of an energy modeling forum study (EMF 29). Energy Econ 34:S97-S110

Böhringer C, Fischer C, Rosendahl KE (2014) Cost-effective unilateral climate policy design: size matters. J Environ Econ Manag 67(3):318-339

Böhringer C, Müller A, Schneider J (2015) Carbon tariffs revisited. J Assoc Environ Resour Econ 2(4):629-672

Böhringer C, Carbone JC, Rutherford TF (2016) The strategic value of carbon tariffs. Am Econ J Econ Policy 8(1):28-51

Böhringer C, Bye B, Fæhn T, Rosendahl KE (2017) Targeted carbon tariffs: export response, leakage and welfare. Resour Energy Econ 50:51-73

Böhringer C, Carbone JC, Rutherford TF (2018) Embodied carbon tariffs. Scand J Econ 120(1):183-210

Branger F, Quirion P (2014) Would border carbon adjustments prevent carbon leakage and heavy industry competitiveness losses? Insights from a meta-analysis of recent economic studies. Ecol Econ 99:29-39

Caldeira K, Davis SJ (2011) Accounting for carbon dioxide emissions: a matter of time. Proc Nat Acad Sci 108(21):8533-8534

Carbone JC, Rivers N (2017) The impacts of unilateral climate policy on competitiveness: evidence from computable general equilibrium models. Rev Environ Econ Policy 11(1):24-42

Dirkse SP, Ferris MC (1995) The path solver: a nommonotone stabilization scheme for mixed complementarity problems. Optim Methods Softw 5(2):123-156

Dröge S (2009) Tackling leakage in a world of unequal carbon prices. Technical Report, September 2009 
Felder S, Rutherford TF (1993) Unilateral $\mathrm{CO}_{2}$ reductions and carbon leakage: the consequences of international trade in oil and basic materials. J Environ Econ Manag 25(2):162-176

Feng K, Davis SJ, Sun L, Hubacek K (2015) Drivers of the US CO 2 emissions 1997-2013. Nat Commun 6(1):7714

Ferris MC, Munson TS (2000) Complementarity problems in GAMS and the PATH solver. J Econ Dyn Control 24(2):165-188

Fischer C, Fox AK (2012) Comparing policies to combat emissions leakage: border carbon adjustments versus rebates. J Environ Econ Manag 64(2):199-216

Ghosh M, Luo D, Siddiqui MS, Zhu Y (2012) Border tax adjustments in the climate policy context: $\mathrm{CO}_{2}$ versus broad-based GHG emission targeting. Energy Econ 34:S154-S167

Graham P, Thorpe S, Hogan L (1999) Non-competitive market behaviour in the international coking coal market. Energy Econ 21(3):195-212

Haites E (2018) Carbon taxes and greenhouse gas emissions trading systems: what have we learned? Clim Policy 18(8):955-966

Hoel M (1991) Global environmental problems: the effects of unilateral actions taken by one country. J Environ Econ Manag 20(1):55-70

Koesler S, Schymura M (2015) Substitution elasticities in a constant elasticity of substitution frameworkempirical estimates using nonlinear least squares. Econ Syst Res 27(1):101-121

Kotchen MJ, Mansur ET (2016) Correspondence: reassessing the contribution of natural gas to US $\mathrm{CO}_{2}$ emission reductions since 2007. Nat Commun 7(1):10648

Krichene N (2002) World crude oil and natural gas: a demand and supply model. Energy Econ 24(6):557-576

Métivier C, Bultheel C, Postic S (2018) Global carbon account 2018. Technical report. Institute for Climate Economics, I4CE, Paris

Monjon S, Quirion P (2011) Addressing leakage in the EU ETS: border adjustment or output-based allocation? Ecol Econ 70(11):1957-1971

Peters GP, Hertwich EG (2008) $\mathrm{CO}_{2}$ embodied in international trade with implications for global climate policy. Environ Sci Technol 42(5):1401-1407

Peters GP, Minx JC, Weber CL, Edenhofer O (2011) Growth in emission transfers via international trade from 1990 to 2008. Proc Nat Acad Sci 108(21):8903-8908

Peterson EB, Schleich J (2007) Economic and environmental effects of border tax adjustments. Working Paper S1/2007, Working paper sustainability and innovation

Reinaud J (2008) Issues behind competitiveness and carbon leakage. focus on heavy industrys. Technical report, International Energy Agency, OECD/IEA

Reinsdorf MB (2010) Terms of trade effects: theory and measurement. Rev Income Wealth 56(s1):S177-S205

Ringlund GB, Rosendahl KE, Skjerpen T (2008) Does oilrig activity react to oil price changes? An empirical investigation. Energy Econ 30(2):371-396

Rutherford TF (1995) Extension of GAMS for complementarity problems arising in applied economic analysis. J Econ Dyn Control 19(8):1299-1324

Timmer MP, Dietzenbacher E, Los B, Stehrer R, Vries GJ (2015) An illustrated user guide to the world input-output database: the case of global automotive production. Rev Int Econ 23(3):575-605

Timmer MP, Los B, Stehrer R, de Vries GJ (2016) An anatomy of the global trade slowdown based on the WIOD 2016 release. Technical Report 162

UNFCCC (1998) Kyoto Protocol To the United Nations framework convention on climate change

UNFCCC (2015) The Paris Agreement

Vivid Economics and Ecofys (2014) Carbon Leakage Prospects Under Phase III of the EU ETS and Beyond-Report prepared for DECC. Technical report

Weitzel M, Hübler M, Peterson S (2012) Fair, optimal or detrimental? Environmental vs. strategic use of border carbon adjustment. Energy Econ 34:S198-S207

Wood R, Grubb M, Anger-Kraavi A, Pollitt H, Rizzo B, Alexandri E, Stadler K, Moran D, Hertwich E, Tukker A (2019) Beyond peak emission transfers: historical impacts of globalization and future impacts of climate policies on international emission transfers. Climate Policy 1-14

World Bank (2018) State and Trends of Carbon Pricing. World Bank

Publisher's Note Springer Nature remains neutral with regard to jurisdictional claims in published maps and institutional affiliations. 